Check for updates

Cite this: RSC Adv., 2018, 8, 35557

Received 16th July 2018

Accepted 3rd October 2018

DOI: $10.1039 / c 8 r a 06028 b$

rsc.li/rsc-advances

\section{Natural iron ore as a novel substrate for the biosynthesis of bioactive-stable ZnOaCuOairon ore NCs: a magnetically recyclable and reusable superior nanocatalyst for the degradation of organic dyes, reduction of $\mathrm{Cr}(\mathrm{vI})$ and adsorption of crude oil aromatic compounds, including PAHs $†$}

\begin{abstract}
S. Mohammad Sajadi, (DD *ab Kamal Kolo, ${ }^{a}$ Mohammad Pirouei, ${ }^{\text {ab }}$ Sarbast A. Mahmud, ${ }^{\text {cd }}$ Jagar. A. Ali ${ }^{a}$ and Samir M. Hamad ${ }^{\text {ae }}$

For the first time, stable $\mathrm{ZnO}$ aCuOairon ore nanocomposites (NCs) were green synthesized using magnetic iron ore as a natural substrate through an eco-friendly, simple and cost-effective method. The biosynthesized nanocatalyst was characterized using the SEM, EDS, elemental mapping, point analysis, XRD, FT-IR, polarized microscopy and UV-vis analytical techniques. The XRD and SEM methods confirmed the excellent stability of the nanocatalyst, even for 6 months. Also, the antioxidant ability of the green-synthesized NCs using a DPPH method was assessed per gallic acid and in contrast with ascorbic acid. Furthermore, their antibacterial activities against the common pathogenic bacteria of Pseudomonas aureus, Staphylococcus aureus and Escherichia coli were evaluated at different concentrations compared to chloramphenicol as a positive control. Moreover, the superior catalytic activity of the ZnOaCuOairon ore NCs was investigated during a series of reactions, including the adsorption of polycyclic aromatic hydrocarbons (PAHs) of heavy crude oil (HCO) obtained from the Shaikhan oil field, the destruction of some organic dyes at room temperature, including methylene blue (MB) and methyl orange (MO), thymol blue (TB), bromothymol blue (BTB), phenol red (Ph.R), methyl red $(\mathrm{MR})$, solochrome black $\mathrm{T}(\mathrm{SBT})$ and eriochrome black $\mathrm{T}(\mathrm{EBT})$ and finally the reduction of $\mathrm{Cr}(\mathrm{VI})$ at ambient temperature using UV-vis spectroscopy. Finally, the magnetic NCs could be simply recovered and reused several times without considerable loss of catalytic activity.
\end{abstract}

\section{Introduction}

Nature shows excellent capability in the synthesis of nanomaterials, in which biological systems are 'bio-laboratories' that produce nanomaterials for use in biomimetic pathways. These pathways are green, energy saving, cost effective and biocompatible for the deposition of biological molecules on the surface of green NPs. ${ }^{1-3}$ The large surface of metal oxide nanoparticles

${ }^{a}$ Scientific Research Center, Soran University, PO Box 624, Soran, KRG, Iraq. E-mail smohammad.sajadi@gmail.com; Tel: +9647503714550; +9647503714551

${ }^{b}$ Department of Petroleum Geosciences, Faculty of Sciences, Soran University, PO Box 624, Soran, KRG, Iraq

'Department of Biology, Faculty of Sciences, Soran University, PO Box 624, Soran, KRG, Iraq

${ }^{d}$ Department of Pharmacy, Rwandz Private Technical Institute, Rawanduz, Soran, KRG, Iraq

${ }^{e}$ Research Center, Cihan University, Erbil, Iraq

$\dagger$ Electronic supplementary information (ESI) available. See DOI: $10.1039 / \mathrm{c} 8 \mathrm{ra} 06028 \mathrm{~b}$ shows a large number of active sites per unit area compared to the parent metal, which in turn, are strongly related to their various applications. Current synthetic methods of NPs restrict their use to some medicinal applications involving the accumulation of poisonous and dangerous materials on a nanoproduct surface. ${ }^{4-7}$ In recent years, natural supporting materials have attracted the attention of researchers for their capacity to prevent the agglomeration and over-stoichiometric use of metal reagents and also to increase the stability of produced nanostructures by altering their sensitivity to oxygen, water and other chemical entities. ${ }^{8,9}$

Plants are a valuable source of some compounds with reductive abilities, called antioxidants. In fact, the antioxidant activity of plants is attributed to the redox potential of phytochemicals to quench singlet and triplet oxygen, decompose peroxides or neutralize free radicals. ${ }^{10-12}$ The higher bioactivity of nanoparticles could also be attributed to the large surfaces of nanoparticles and preferential adsorption of the bioactive constituents from an extract onto the surface of the 
nanoparticles, both of which are strongly affected by the surface area, particle size and surface reactivity of the nanoparticles. ${ }^{\mathbf{1 3 - 1 9}}$

The toxicity and carcinogenic characteristics of organic dyes represent a series of problematic challenges to human life, thus developing efficient treatment methods to ensure the removal of organic dye pollutants is an essential requirement. The large surface area of nanostructures enhances significantly their ability in the catalytic degradation of organic dyes. Among the nanostructures, the green-synthesized ones have increasingly become the subject of many studies, as they do not show the side effects and the difficulties involved in use of the previous methods. One aim of this research was to study the ability and the efficiency of green-synthesized ZnO@CuO@iron ore NCs in the destruction of a wide spectrum of harmful organic dyes. ${ }^{20-22}$

$\operatorname{Cr}(\mathrm{vI})$ is one of the most dangerous heavy metals in the environment, and due to its solubility in water, its removal has challenged many researchers in recent years. Up to now, most studies on the removal of $\mathrm{Cr}(\mathrm{vI})$ have been based on its conversion to $\mathrm{Cr}(\mathrm{III})$, which has low toxicity and is easily eliminated through the formation of insoluble hydroxides by adjusting the $\mathrm{pH}$ in aqueous media. Recently, other reaction processes have focused on the reduction of $\mathrm{Cr}(\mathrm{vI})$. Most of these methods have problems, such as the production of secondary wastes and toxic by-products. ${ }^{23,24}$ This study uses ZnO@CuO@iron ore NCs as a highly efficient nanocatalyst to aid the removal of hexavalent chromium.

Polycyclic aromatic hydrocarbon (PAH) compounds are lipophilic and highly soluble in organic solvents and include fused aromatic rings with various toxicities produced mainly via the incomplete combustion and pyrolysis of materials containing carbon and hydrogen, such as coal, oil, wood and petroleum products. ${ }^{25,26}$ Many reports have confirmed that aromatic compounds, especially PAHs, are toxic and environmentally persistent with carcinogenic, immune suppressant and mutagenic effects. The main sources of polyaromatic compounds are pyrogenic, petrogenic and biological processes, in which those produced from petrogenic sources are the most widespread pollutants due to the considerable transportation, storage and application of crude oil and its products. ${ }^{27,28}$ This research work investigates the catalytic ability of the NCs to adsorb aromatic hydrocarbons, including PAHs, from Shaikhan crude oil.

The Shaikhan block is a large oilfield discovered in Iraqi Kurdistan in the last decade. The field was explored and developed by Gulf Keystone Petroleum Limited, see ESI, Fig. 1. $\dagger$

Bryonia dioica from the family Cucurbitaceae is indigenous to many parts of Europe and West Asia and is well distinguished from the other Bryonia species by its black fruits and monoecious flowers. ${ }^{29,30}$ Among the significant phytochemical content of Bryonia are alkaloid bryonicine and antioxidant flavonoids, such as saponarin, vitexin, isovitexin, 5,7,4'-trihydroxy flavone 8-C-glucopyranoside, lutonarin, isoorientin; glycosides, and also triterpenoids, cucurbitacin L, 23,24-dihydrocucurbitacin B, 23,24-dihydrocucurbitacin D, arvenin IV and also lipids, which are of special importance. ${ }^{31,32}$ The rich phytochemical content of the plant reported in the literature and the ability of its extract to reduce metal ions has made it a strong candidate for the synthesis of $\mathrm{ZnO} @ \mathrm{CuO} @$ iron ore NCs in a green way and the evaluation of its stability, bioactivities and applications, ESI, Fig. $2 . \dagger$

This study for the first time employed both the Bryonia dioica root extract as an antioxidant bioreducing, stabilizing and capping source and natural iron ore as a novel green substrate to synthesize $\mathrm{ZnO} @ \mathrm{CuO}$ (aron ore NCs as a green nanocatalyst. In fact, this natural substrate increases the synergic effect, stabilizing factor and prevents the agglomeration of anchoring nanoparticles. Furthermore, the stability and bioactivity of the nanocatalyst, including antioxidant activity (in contrast to ascorbic acid's antioxidant ability) and antibacterial activity against common pathogenic bacteria of Pseudomonas aureus, Staphylococcus aureus and Escherichia coli, were investigated. Also, the catalytic activity and adsorption ability of bioactive NCs was monitored during the destruction process of a wide series of harmful organic dyes, adsorption of the aromatic contents of Shaikhan crude oil and reduction of $\mathrm{Cr}(\mathrm{vI})$ at ambient temperature.

\section{Experimental}

\section{Reagents and methods}

High-purity chemicals were purchased from Merck and Aldrich chemical companies. X-ray diffraction (XRD) measurements were carried out using a Philips powder diffractometer type PW 1373 goniometer with scanning rate of $2^{\circ} \mathrm{min}^{-1}$ in the $2 \theta$ range from $0^{\circ}$ to $90^{\circ}$. UV-visible spectra for analysis were recorded on a double-beam spectrophotometer (Super Aquarius) to monitor the SPR signals of the nanoparticles. The morphology, particle dispersion and chemical composition of the prepared nanostructures were investigated by fast emission scanning electron microscopy (FE-SEM) (Quanta 450) equipped with EDS (energy dispersive X-ray spectroscopy). FT-IR spectra were recorded on a Nicolet $370 \mathrm{FT} / \mathrm{IR}$ spectrometer (Thermo Nicolet, USA) using pressed $\mathrm{KBr}$ pellets. The antibacterial activity of the greensynthesized ZnO@CuO@iron ore NCs was studied using the disc diffusion method via Muller-Hinton media and by using chloramphenicol as positive control. The Pseudomonas aureus, Staphylococcus aureus and Escherichia coli were obtained from the Department of Biology, Soran University in KRG, Iraq.

\section{Plant materials}

The root of Bryonia dioica plant was collected in summer 2017 in the Haji Umran alpine region (at an elevation of 1705 metres above sea level) in Iraqi Kurdistan and identified by the Department of Biology of Soran University in Arbil, KRG, Iraq, Fig. 2.

\section{Preparation of the Bryonia dioica root extract}

First, $30.0 \mathrm{~g}$ of dried root powder of the plant was boiled in $300 \mathrm{~mL}$ double distilled water for $45 \mathrm{~min}$ at $80{ }^{\circ} \mathrm{C}$. The obtained extract was centrifuged at $7000 \mathrm{rpm}$ and then filtered and used for further steps of the study. 


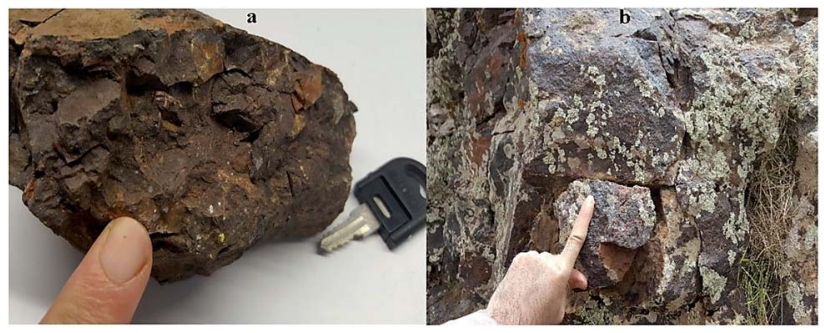

Fig. 1 Iron ore: (a) hand specimen, (b) natural outcrop setting

\section{Magnetic iron ore collection}

The iron ore deposit was collected in the north west of Choman, Erbil governorate, Iraqi Kurdistan, Fig. 1. The sample was washed with hot water to remove possible impurities then dried and powdered to be used as a natural magnetic support during this study.

\section{One-pot green synthesis of ZnO@CuO@iron ore NCs}

In a $250 \mathrm{~mL}$ flask, $1 \mathrm{~g}$ dried powdered iron ore was mixed with $100 \mathrm{~mL}$ plant extract, then $50 \mathrm{~mL} 0.6 \% \mathrm{CuCl}_{2} \cdot 2 \mathrm{H}_{2} \mathrm{O}$ and $0.2 \%$ $\mathrm{Zn}\left(\mathrm{NO}_{3}\right)_{2}$ solutions were added dropwise, respectively, to the mixture in an alkaline media that was adjusted using $0.1 \mathrm{M}$ $\mathrm{Na}_{2} \mathrm{CO}_{3}$ at $\mathrm{pH} 9$ with stirring at $80{ }^{\circ} \mathrm{C}$ until the colour of the mixture changed and formation of the precipitation occurred. The precipitation was then separated and heated at $105^{\circ} \mathrm{C}$ for $2 \mathrm{~h}$ for autooxidation and formation of the $\mathrm{ZnO} @ \mathrm{CuO} @ i$ iron ore NCs. The obtained precipitate of NCs was washed with cool distillate water, then dried and kept for identification and application processes. The stability of the green nanocatalyst was detected using XRD analysis for six months after its synthesis.

\section{Antimicrobial activity}

Pseudomonas aureus, Staphylococcus aureus and Escherichia coli bacterial strains were used to evaluate the antibacterial activity of samples through a disc diffusion method by the standard protocol. ${ }^{33}$ Briefly, the overnight bacterial cultures $(100 \mu \mathrm{L})$ were introduced over Muller-Hinton agar plates with a sterile glass rod. The minimum inhibition concentration (MIC) was determined for each sample, see Table 1. Also, the positive and negative controls were chloramphenicol and the discs were prepared using sterile distilled water. Briefly, $100 \mu \mathrm{L}$ of the NCs and chloramphenicol (under the same conditions) were loaded on to the provided discs ( $6 \mathrm{~mm} \mathrm{D}$ ) and allowed to dry before being placed on the agar. The plates were inoculated at $37^{\circ} \mathrm{C}$ for $24 \mathrm{~h}$ after incubation. Finally, the diameter of the inhibition zones was measured and tabulated.

\section{Antioxidant activity using the DPPH radical scavenging method}

The antioxidant potential of the green-fabricated NCs against 2,2-diphenyl-1-picrylhydrazyl (DPPH) was determined using the method described by Clarke et al. ${ }^{34}$ Briefly, a $1: 1$ ratio of test sample (NCs) and ascorbic acid (for comparison) at different concentrations were mixed with freshly prepared DPPH
Table 1 Antibacterial activity of Bryonia dioica root extract and ZnOaCuOairon ore NCs

\begin{tabular}{lccc}
\hline Compounds & P. aureus & S. aureus & E. coli \\
\hline Plant extract & $19 \mathrm{~mm}$ & $16 \mathrm{~mm}$ & $13 \mathrm{~mm}$ \\
ZnO@CuO@iron ore NCs (1\%) & $29 \mathrm{~mm}$ & $33 \mathrm{~mm}$ & $28 \mathrm{~mm}$ \\
ZnO@CuO@iron ore NCs (2\%) & $37 \mathrm{~mm}$ & $45 \mathrm{~mm}$ & $47 \mathrm{~mm}$ \\
${ }^{a}$ Chloramphenicol & $13 \mathrm{~mm}$ & $8 \mathrm{~mm}$ & $13 \mathrm{~mm}$ \\
${ }^{a} \mathrm{C}^{+}$; chloramphenicol disc diameter (positive control). &
\end{tabular}

solution in a test tube and kept in the dark for $30 \mathrm{~min}$, respectively. Absorbance at $517 \mathrm{~nm}$ was measured with a UV-vis spectrophotometer and compared to an ascorbic acid inhibition curve. Furthermore, gallic acid was used as a control for both samples. Each assay was carried out in triplicate. The percentage inhibition of the DPPH radical was calculated using the following equation:

$$
\begin{aligned}
& \text { Radical Scavenging Activity }(\mathrm{RSA} \%) \text { or Inhibition } \\
& \qquad(\operatorname{In} \%)=\left[\left(A_{\mathrm{c}}-A_{\mathrm{t}}\right) / A_{\mathrm{c}}\right] \times 100
\end{aligned}
$$

where In is the DPPH inhibition (\%), $A_{\mathrm{c}}$ is the absorbance of the control and $A_{\mathrm{t}}$ is the absorbance of the samples. The amounts of both the NCs and ascorbic acid required to decrease the absorbance of DPPH by $50 \%\left(\mathrm{IC}_{50}\right)$ were calculated graphically as the mean value \pm standard deviation and the results compared.

\section{Reduction of organic dyes by ZnO@CuO@iron ore NCs}

First, $20 \mathrm{~mL}$ of $3 \times 10^{-5} \mathrm{M}$ aqueous solution of $\mathrm{MO}$ (in the case of MB, TB, BTB, Ph.R, MR, SBT and EBT solution, the concentrations were the same, respectively) was added to $5 \mathrm{mg}$ of ZnO@CuO@iron ore NCs (in the case of MB, TB, BTB, Ph.R, MR, SBT and EBT solutions, the employed catalyst amount was 3, 1, 2, 3, 3, 7 and $10 \mathrm{mg}$, respectively, Table 2) at room temperature. Then, $20 \mathrm{~mL}$ of freshly prepared aqueous solution of $\mathrm{NaBH}_{4}\left(5.3 \times 10^{-3}\right)$ was added to the mixture with stirring at room temperature. The progress of the degradation reaction was monitored by recording the time-dependent UV-vis absorption spectra of the mixture. At the end of the reaction, the catalyst was simply separated from the reaction system by filtration and washed with ethanol and dried for the next cycle of the process, see ESI, Fig. $3 . \dagger$

\section{Catalytic activity of the green-synthesized ZnO@CuO@iron ore NCs for the reduction of $\mathrm{Cr}(\mathrm{vi})$}

To study the catalytic ability of ZnO@CuO@iron ore NCs to reduce hexavalent chromium, the reduction of potassium dichromate $\left(\mathrm{K}_{2} \mathrm{Cr}_{2} \mathrm{O}_{7}\right)$ by formic acid was used as a model system. Here, $5.0 \mathrm{mg}$ of the $\mathrm{ZnO@CuO@iron} \mathrm{ore} \mathrm{NCs} \mathrm{was}$ added to $25 \mathrm{~mL}$ of aqueous solution of $3.5 \mathrm{mM} \mathrm{Cr}(\mathrm{vI})$. Then, $1.0 \mathrm{~mL}$ formic acid solution (90\%) was added to the mixture under constant stirring at $50{ }^{\circ} \mathrm{C}$. The reaction progress with time was monitored using a UV-vis spectrophotometer. After the end of the reaction process, the catalyst was washed using distilled water and then dried to use in the next cycle of the reaction. 
Table 2 Reduction time of dyes using different amounts of $\mathrm{ZnO}$ aCuOairon ore NCs

\begin{tabular}{|c|c|c|c|c|}
\hline Entry & Dye (M) & $\mathrm{NaBH}_{4}(\mathrm{M})$ & Catalyst $^{a}(\mathrm{mg})$ & Time (s) \\
\hline 1 & MO & $5.3 \times 10^{-3}$ & 3 & $2 \min ^{b}$ \\
\hline 2 & MO & $5.3 \times 10^{-3}$ & 5 & $26 s$ \\
\hline 3 & MO & $5.3 \times 10^{-3}$ & 8 & $31 \mathrm{~s}$ \\
\hline 4 & MO & $5.3 \times 10^{-3}$ & 10 & $55 \mathrm{~s}$ \\
\hline 5 & MB & $5.3 \times 10^{-3}$ & 1 & $1 \min ^{b}$ \\
\hline 6 & MB & $5.3 \times 10^{-3}$ & 3 & $15 \mathrm{~s}$ \\
\hline 7 & MB & $5.3 \times 10^{-3}$ & 5 & $28 \mathrm{~s}$ \\
\hline 8 & MB & $5.3 \times 10^{-3}$ & 7 & $29 \mathrm{~s}$ \\
\hline 9 & BTB & $5.3 \times 10^{-3}$ & 2 & $20 \mathrm{~s}$ \\
\hline 10 & BTB & $5.3 \times 10^{-3}$ & 5 & $22 \mathrm{~s}$ \\
\hline 11 & ВТВ & $5.3 \times 10^{-3}$ & 7 & $22 \mathrm{~s}$ \\
\hline 12 & BTB & $5.3 \times 10^{-3}$ & 10 & $22 \mathrm{~s}$ \\
\hline 13 & MR & $5.3 \times 10^{-3}$ & 2 & $27 \mathrm{~s}$ \\
\hline 14 & MR & $5.3 \times 10^{-3}$ & 3 & $20 \mathrm{~s}$ \\
\hline 15 & MR & $5.3 \times 10^{-3}$ & 4 & $26 \mathrm{~s}$ \\
\hline 16 & EBT & $5.3 \times 10^{-3}$ & 2 & $2 \min ^{b}$ \\
\hline 17 & EBT & $5.3 \times 10^{-3}$ & 5 & $102 \mathrm{~s}$ \\
\hline 18 & EBT & $5.3 \times 10^{-3}$ & 7 & $66 \mathrm{~s}$ \\
\hline 19 & EBT & $5.3 \times 10^{-3}$ & 10 & $50 \mathrm{~s}$ \\
\hline 20 & TB & $5.3 \times 10^{-3}$ & 1 & $12 \mathrm{~s}$ \\
\hline 21 & $\mathrm{~TB}$ & $5.3 \times 10^{-3}$ & 2 & $18 \mathrm{~s}$ \\
\hline 22 & TB & $5.3 \times 10^{-3}$ & 3 & $18 \mathrm{~s}$ \\
\hline 23 & Ph.R & $5.3 \times 10^{-3}$ & 1 & $18 \mathrm{~s}$ \\
\hline 24 & Ph.R & $5.3 \times 10^{-3}$ & 2 & $16 \mathrm{~s}$ \\
\hline 25 & Ph.R & $5.3 \times 10^{-3}$ & 3 & $10 \mathrm{~s}$ \\
\hline 26 & Ph.R & $5.3 \times 10^{-3}$ & 5 & $10 \mathrm{~s}$ \\
\hline 27 & SBT & $5.3 \times 10^{-3}$ & 3 & $41 \mathrm{~s}$ \\
\hline 28 & SBT & $5.3 \times 10^{-3}$ & 5 & $34 \mathrm{~s}$ \\
\hline 29 & SBT & $5.3 \times 10^{-3}$ & 7 & $25 \mathrm{~s}$ \\
\hline 30 & SBT & $5.3 \times 10^{-3}$ & 10 & $25 \mathrm{~s}$ \\
\hline 31 & Org. $\mathrm{D}^{c}$ & Absent & Diff. $\mathrm{A}^{d}$ & No reaction \\
\hline 32 & Org.D & $5.3 \times 10^{-3}$ & Absent & No reaction \\
\hline
\end{tabular}

${ }^{a}$ ZnO@CuO@iron ore NCs. ${ }^{b}$ Not completed. ${ }^{c}$ Org.D: organic dyes. ${ }^{d}$ Diff.A: different amounts.

Catalytic ability of the green-synthesized ZnO@CuO@iron ore NCs for the adsorption of crude oil aromatics

The catalytic activity of green-synthesized NCs was monitored according to the details in ESI, Scheme $1 . \dagger$ Briefly, $50 \mathrm{~mL}$ of the heavy crude oil sample was impregnated on $5 \mathrm{~g}$ silica gel $\left(\mathrm{G}^{*} 60\right)$ and mixed to $100 \mathrm{~mL}$ distilled water under reflux conditions at $80{ }^{\circ} \mathrm{C}$ for $30 \mathrm{~min}$ to remove the possible salts and inorganic interferences. After separation of the water phase, the oil sample was added to a mixture of methanol : diethyl ether: benzene $(3: 1: 1)$ and then ultrasonicated at $60{ }^{\circ} \mathrm{C}$ to obtain the aromatics and PAHs. In the next step, the different amounts of the ZnO@CuO@iron ore NCs were added to $20 \mathrm{~mL}$ of the extracted aromatics and ultrasonicated at $60{ }^{\circ} \mathrm{C}$ to study the effect of the catalyst amount on the rate of the adsorption process, Table 2 . Finally, the nanocatalyst was separated from the mixture and washed with $n$-hexane and absolute ethanol, then dried to use in the next cycle of the process. The catalytic adsorption process was monitored using UV-vis spectroscopy to study the efficiency of the catalyst to adsorb the aromatic compounds.

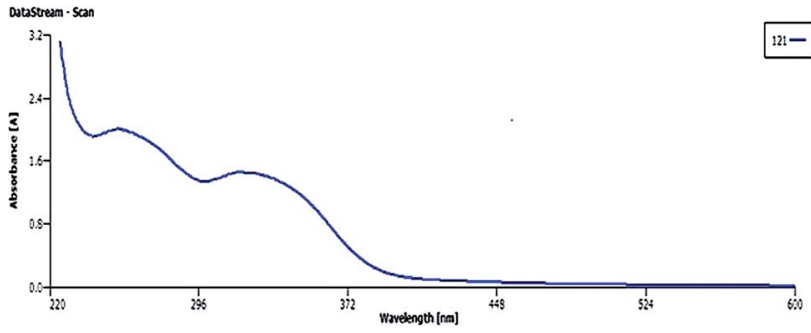

Fig. 2 UV-vis spectroscopy of Bryonia dioica root extract.

\section{Results and discussion}

Bryonia dioica root extract was used as antioxidant media to synthesize both $\mathrm{ZnO}$ and $\mathrm{CuO}$ NPs and for their immobilization on iron ore as a novel support containing different types of minerals for the one-pot biosynthesis of bioactive stable ZnO@CuO@iron ore NCs, Scheme 1. The green nanocatalyst was absolutely identified by various techniques, such as FESEM, EDS, XRD, FT-IR and UV-vis spectroscopy. Furthermore, the stability, bioactivity and catalytic ability of the prepared iron ore based nanocatalyst were studied.

\section{Characterization of Bryonia dioica extract}

Fig. 2 shows the UV-vis signals of plant extract at $320 \mathrm{~nm}$ (bond I) and $267 \mathrm{~nm}$ (bond II) assigned to the cinnamoyl and benzoyl systems of antioxidant phenolics, respectively. ${ }^{35}$
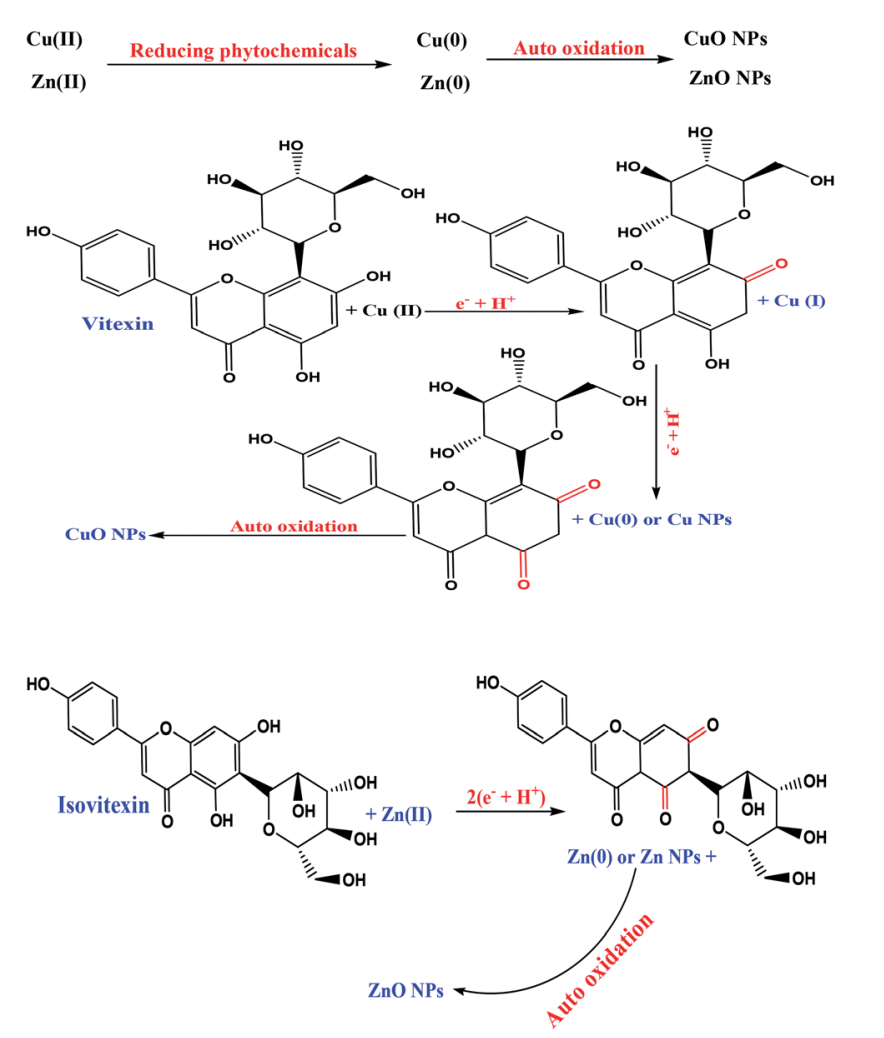

Scheme 1 Green-synthesis mechanism of ZnO NPs and CuO NPs using the antioxidant extract of the Bryonia dioica extract. 


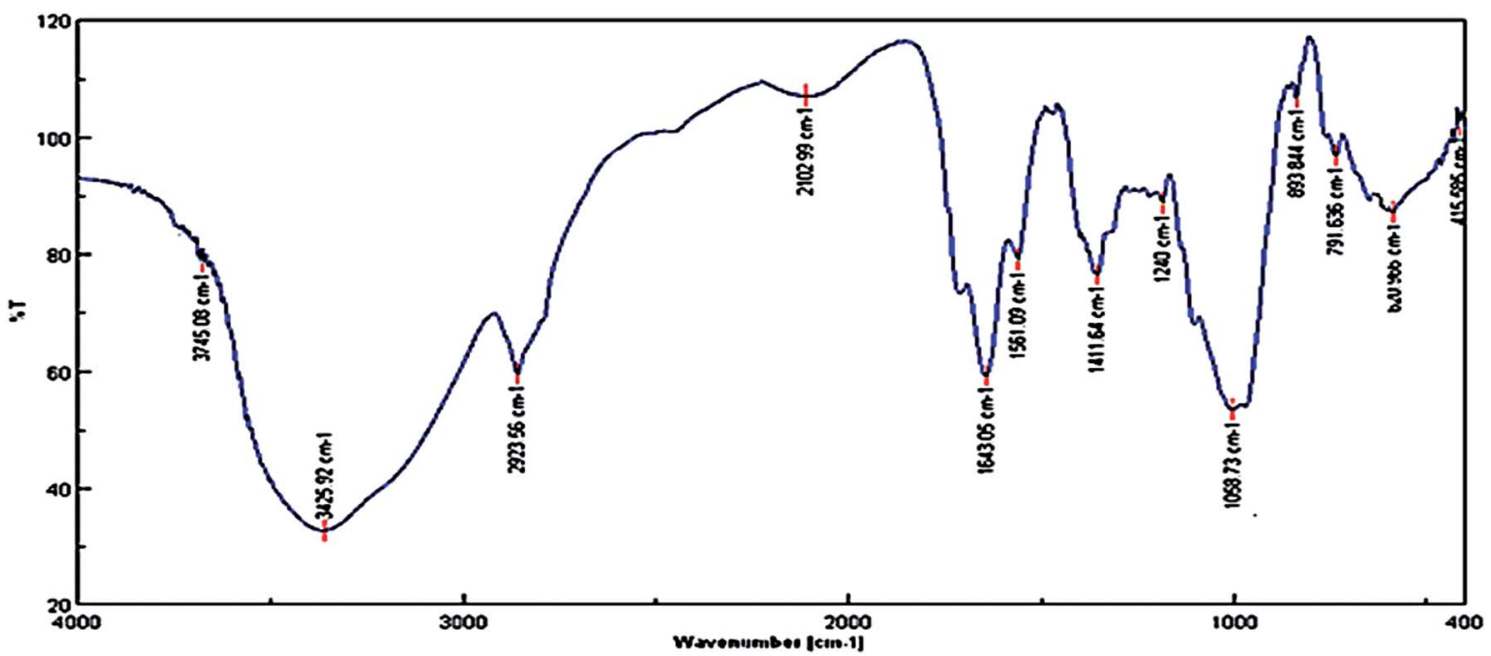

Fig. 3 FT-IR signals of the plant leaf extract.

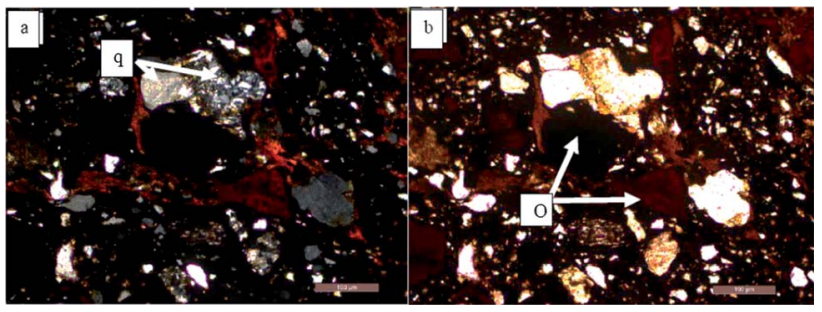

Fig. 4 Polarized microscopy image of iron ore sample; (a) and (b) show the microscopic pictures of ore body containing quartz (q) and opaque minerals $(\mathrm{O})$.

The signals around 3425, 1643, 1411 and 1300 to $1000 \mathrm{~cm}^{-1}$ correspond to the $\mathrm{OH}$, carbonyl group $(\mathrm{C}=\mathrm{O})$, stretching $\mathrm{C}=\mathrm{C}$ aromatic ring and $\mathrm{C}-\mathrm{O}$ vibrations, respectively, Fig. 3. Therefore, the obtained results by FT-IR and UV-vis analysis support the reported results in previous literature, indicating the presence of phenolic antioxidants inside the plant extract.

\section{Identification of natural iron ore substrate}

From a geological point of view, the ore body was located at Choman in the Iraqi Zagros thrust zone (IZTZ), which belongs to the Alpine-Himalayan orogenic belt.

As Fig. 1 shows, the appearance of the iron ore hand sample is black coloured with high density, which contains large crystals of quartz. In fact, according to mineralogical studies of the ore body by polarized microscopy and X-ray diffraction (XRD) analysis, the ore is composed of quartz, magnetite, hematite, and chromite, Fig. 4.

Fig. 5 depicts the XRD analysis of the iron ore substrate. According to this diagram, the sample includes various mineral constituents, especially a suitable amount of magnetite, which supports the excellent magnetic properties of the iron ore sample. Also, from the XRD diagram of the sample, a homogenous crystalline structure involving magnetite, hematite, quartz and chromite constituents can be simply monitored.

For more convenience about the structural and constitutional elucidation of the natural iron ore sample, the surface morphology and elemental constituents of the sample were

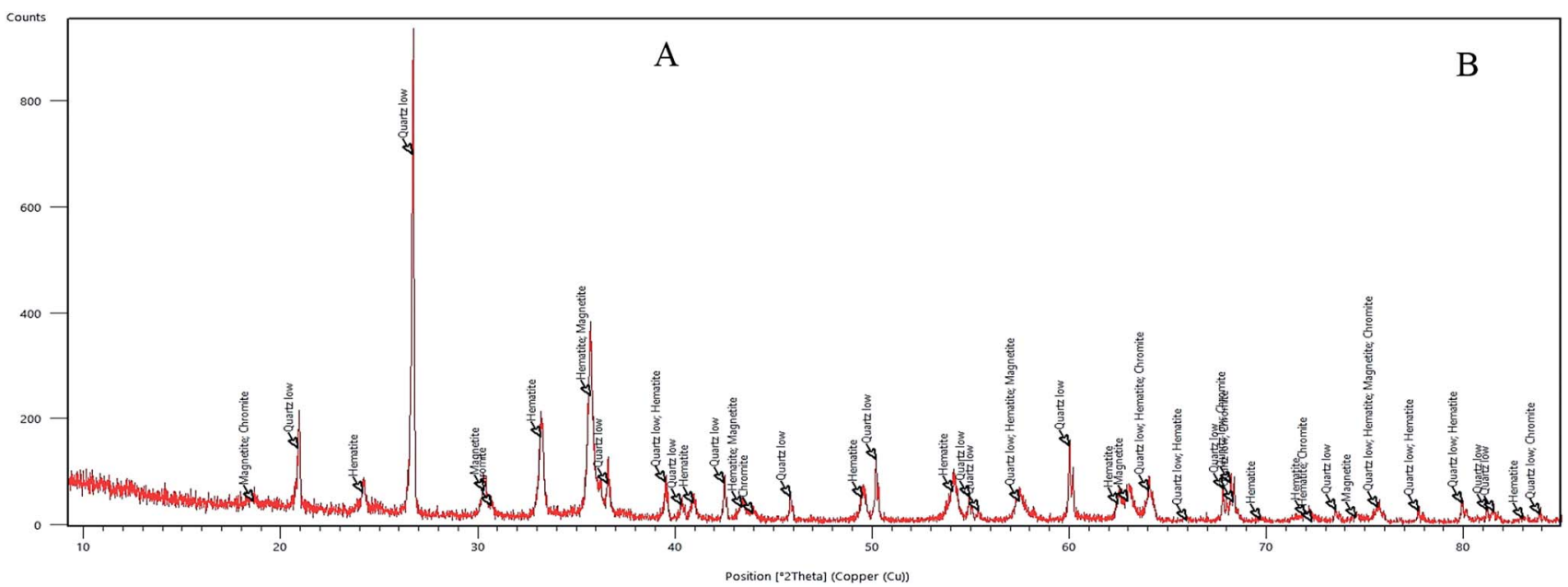

Fig. 5 XRD diagram of natural iron ore substrate. 


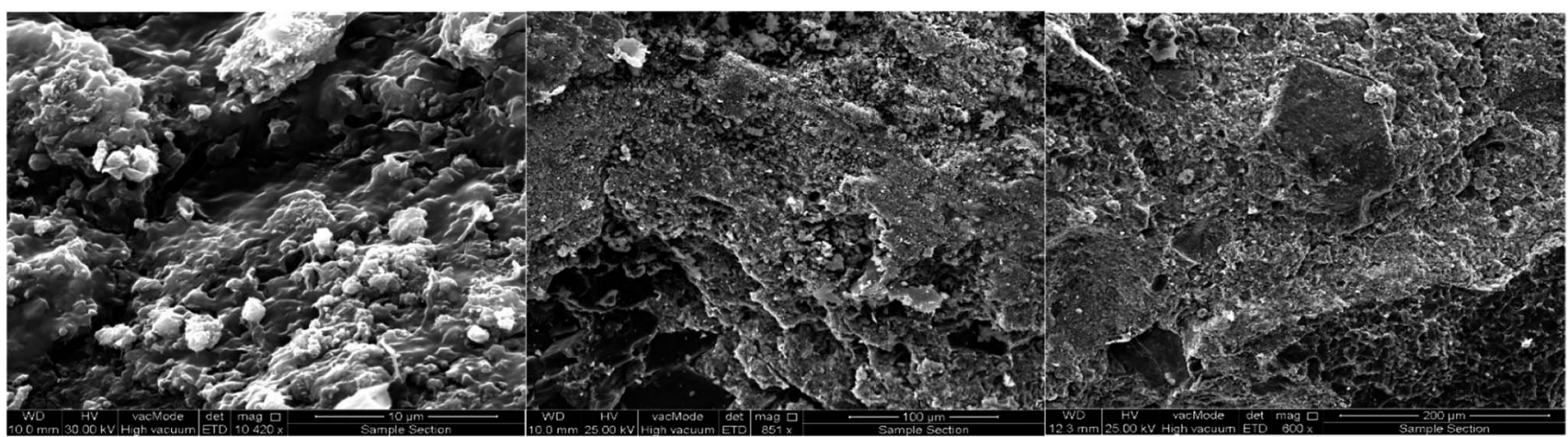

Fig. 6 SEM micrograph of natural iron ore substrate.

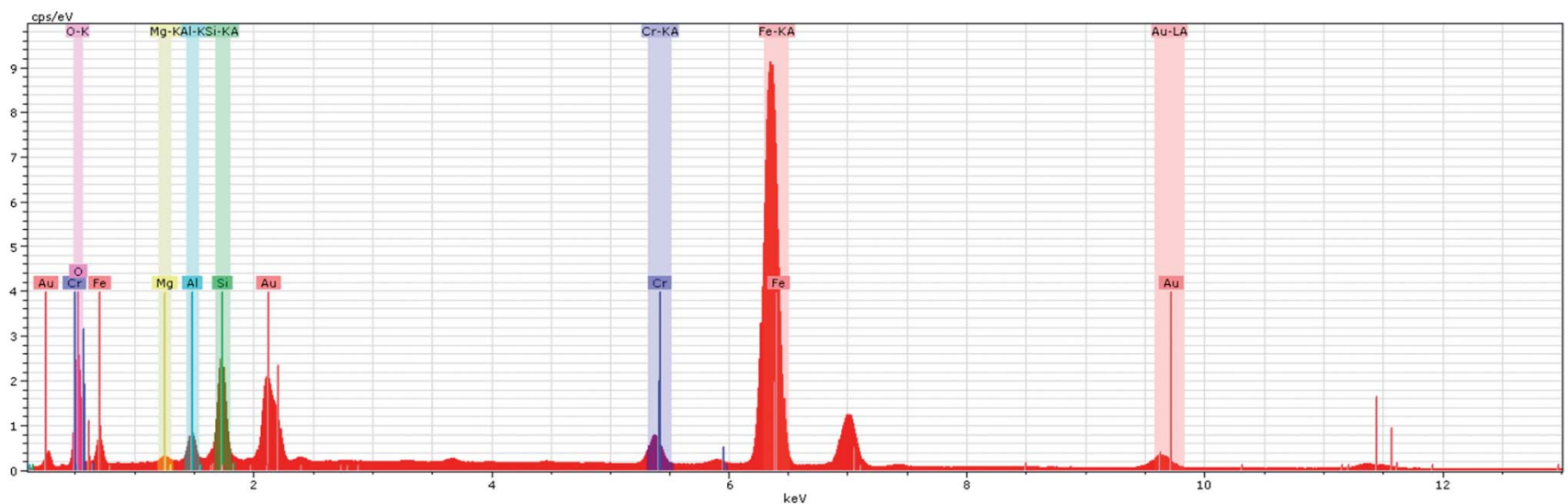

Fig. 7 EDS micrograph of natural iron ore substrate.

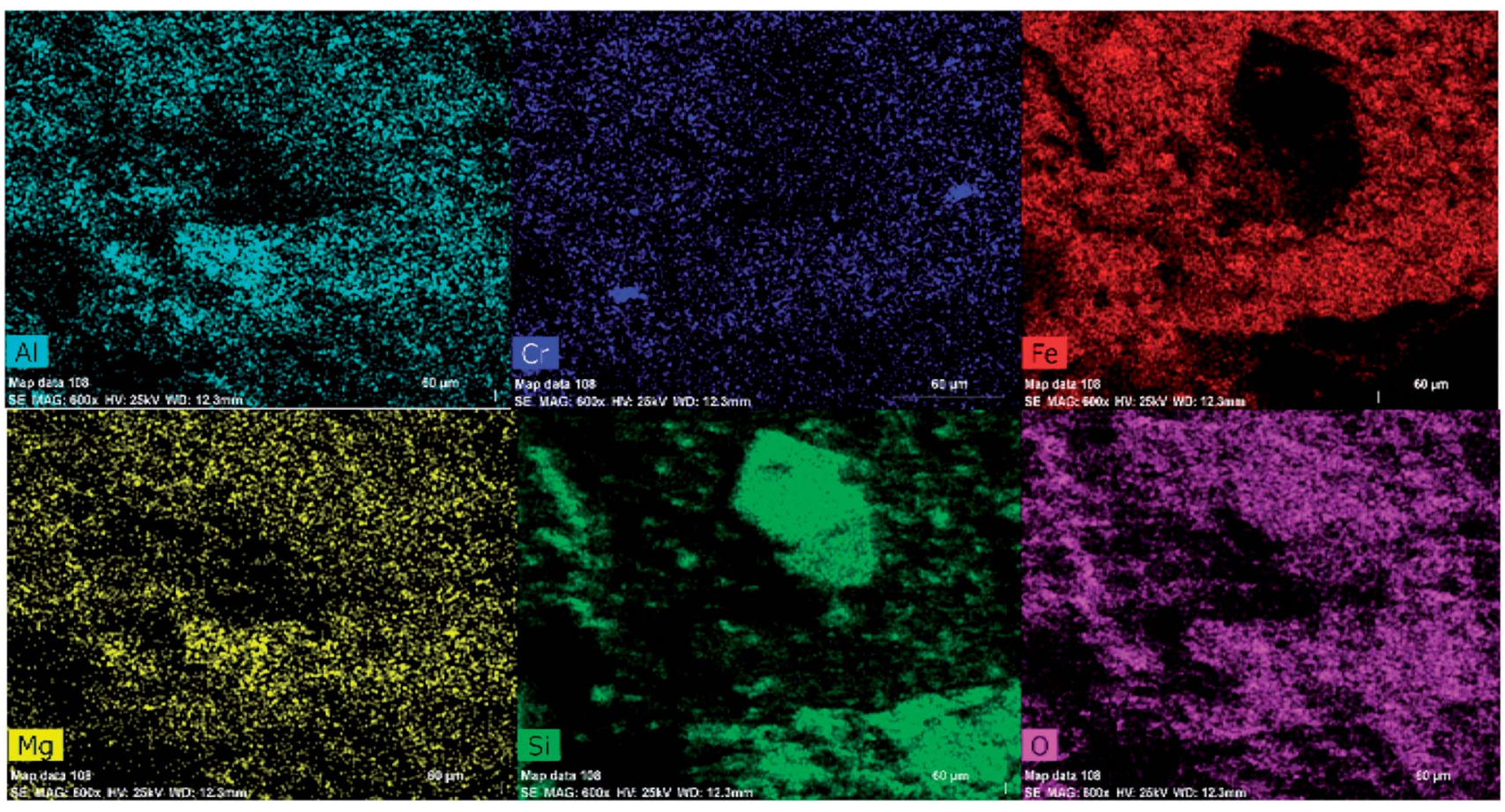

Fig. 8 Elemental mapping of the green-synthesized ZnO@CuO@iron ore NCs. 


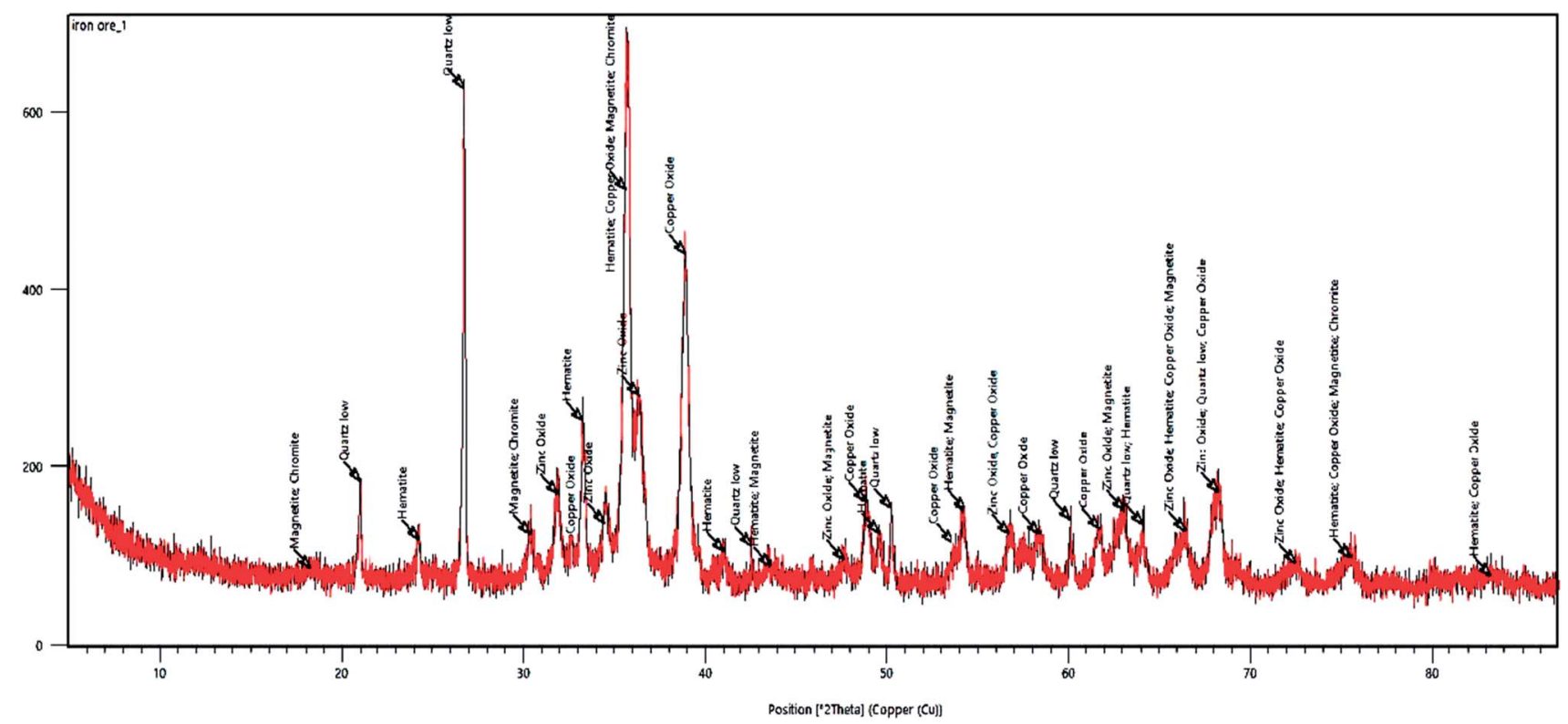

Fig. 9 XRD pattern of green-synthesized NCs.

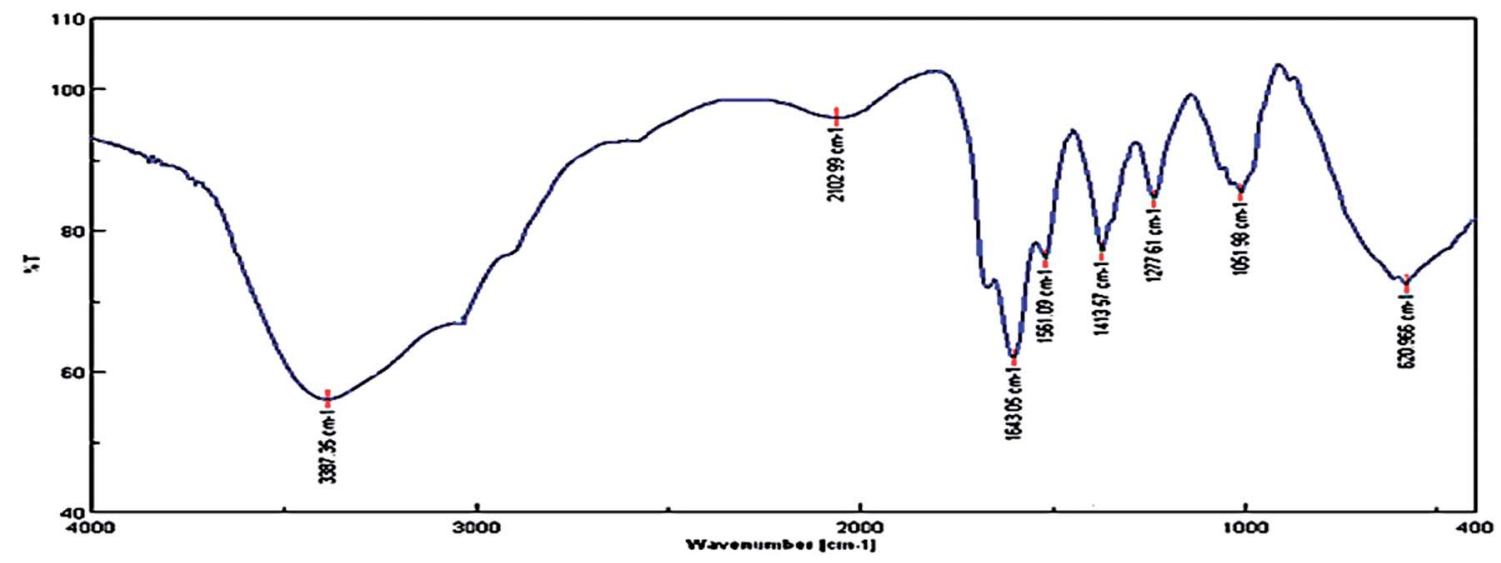

Fig. 10 FT-IR spectrum of the green-synthesized nanocomposite.

investigated with FE-SEM, EDS and elemental mapping, as depicted in Fig. 6-8. As concluded from the iron ore morphology, the SEM and EDS results show the presence of phases that are mainly enriched in $\mathrm{Fe}, \mathrm{Si}, \mathrm{Cr}, \mathrm{Al}$ and $\mathrm{Mg}$. Chromium, $\mathrm{Al}, \mathrm{Mg}$ and some amount of $\mathrm{Fe}$ are concentrated in chromite minerals with a size of 20-120 micron, with the silica concentrated inside quartz grains as a single crystal with a size of 60 micron, and also in most areas as anhedral and fine grained and distributed unevenly inside the sample. Magnetite and hematite are the minerals of iron as a single grain (magnetite) and also in matrix (hematite).

\section{Green synthesis and characterization of the ZnO@CuO@iron ore NCs}

The ZnO@CuO@iron ore NCswere synthesized using the natural based iron ore and Bryonia dioica extracts without the need for the application of toxic, hazardous or dangerous materials, such as surfactants and reductants. The crystallinity of the green- synthesized NCs is depicted in the XRD pattern in Fig. 9, which clearly shows the characteristic peaks of the crystal planes of various crystalline minerals, especially $\mathrm{ZnO}$ and CuO NPs.

The XRD signals of $\mathrm{ZnO}$ NPs at $31.841^{\circ}, 34.507^{\circ}, 36.324^{\circ}$, $47.592^{\circ}, 56.634^{\circ}, 62.895^{\circ}, 66.426^{\circ}, 67.983^{\circ}, 69.091^{\circ}$ and $72.987^{\circ}$ show the (100), (002), (101), (102), (110), (103), (002), (112), (201) and (202) planes, respectively, which obviously show its crystalline monoclinic structure. Furthermore, Fig. 9 shows the crystalline nature of the CuO NPs. The XRD pattern indicates that the $\mathrm{CuO}$ nanoparticles had a face-centred cubic (fcc) structure. The CuO NPs had a similar diffraction profile observed to be at $32.47^{\circ}, 35.49^{\circ}, 38.68^{\circ}, 48.85^{\circ}, 53.36^{\circ}, 58.25^{\circ}$, $61.45^{\circ}, 68.45^{\circ}, 72.31^{\circ}$ and $75.48^{\circ}$, which were assigned to the (110), (111), (200), (202), (020), (202), (113), (311), (220) and (400) crystallographic planes of the face-centred cubic (fcc) crystals.

The FT-IR analysis of the nanocomposite strongly confirmed the deposition of phytochemicals on the surface of the 


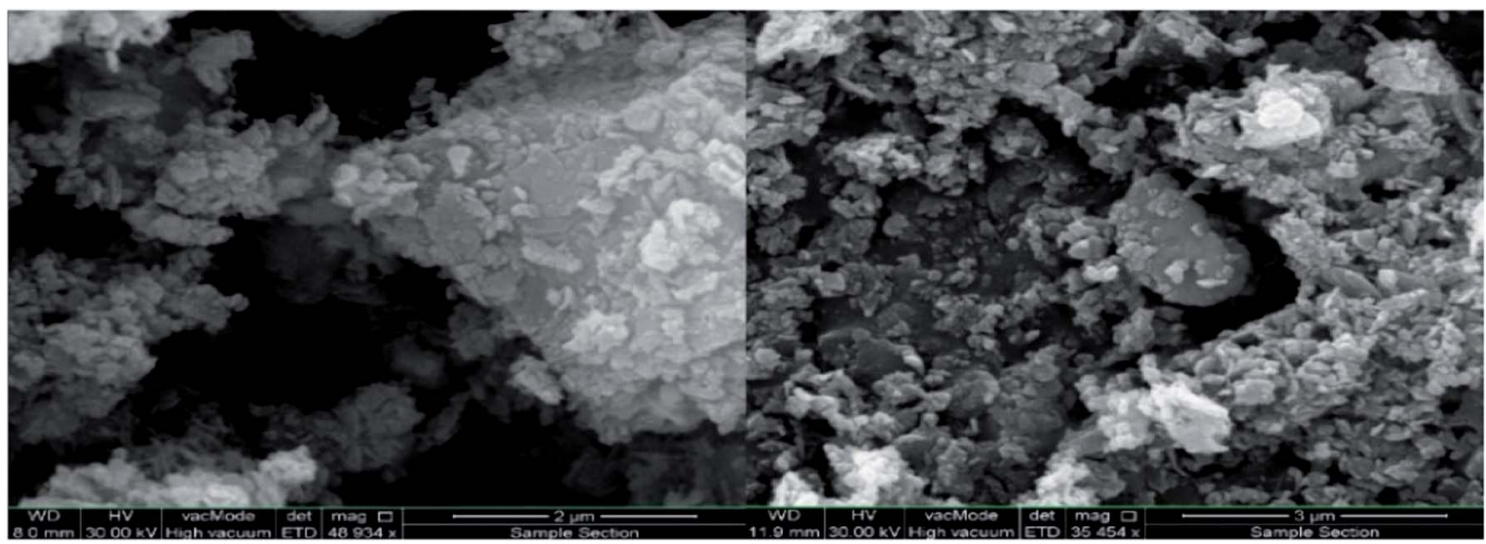

Fig. 11 FE-SEM micrograph of green-synthesized ZnO@CuO@iron ore NCs.

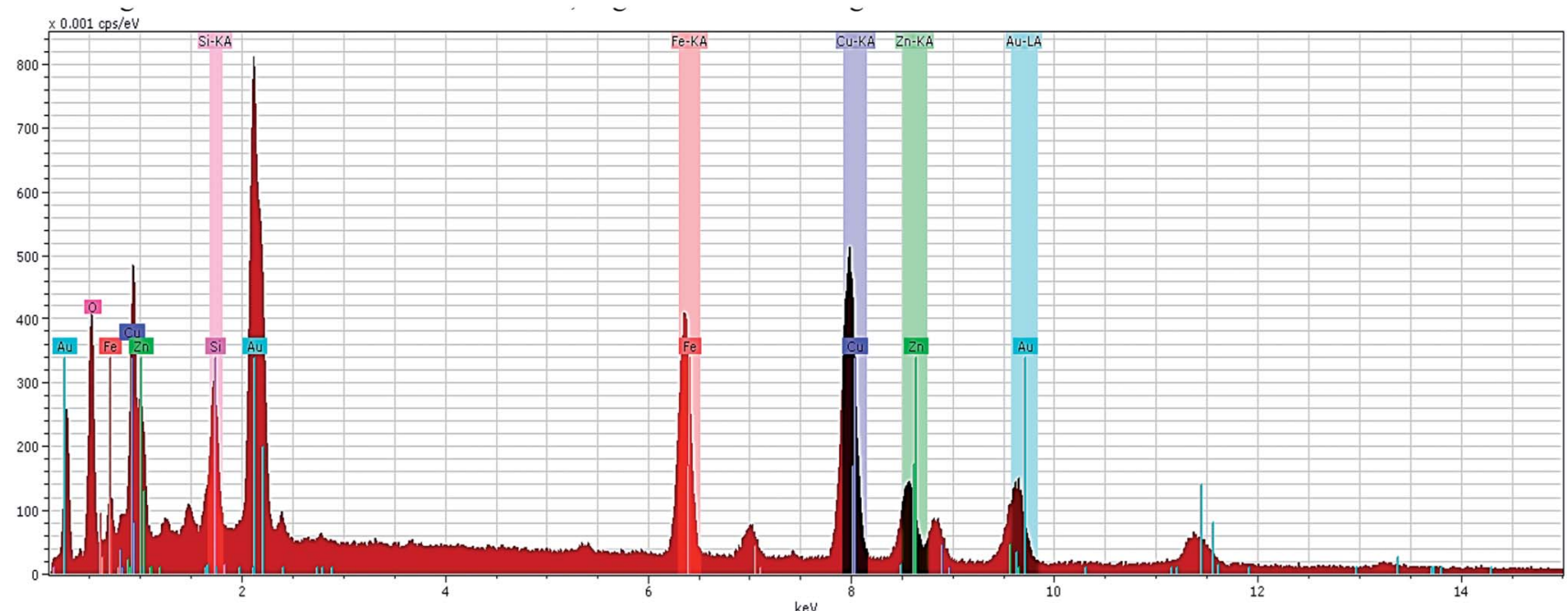

Fig. 12 EDS spectrum of green-synthesized $\mathrm{ZnO}$ aCuO@iron ore.

nanostructure. The main peaks at 3387,1643 and $1561 \mathrm{~cm}^{-1}$ are assigned to the functional groups of $\mathrm{OH}, \mathrm{C}=\mathrm{O}$ and $\mathrm{C}=\mathrm{C}$ aromatic vibrations, respectively, Fig. 10. Therefore, the presence of bioactive phytochemicals on the surface of biosynthesized NCs, as depicted by the FT-IR spectrum, strongly justified the bioactivity of the green-synthesized NCs.
In the next step, the preparation of the $\mathrm{ZnO@CuO@iron} \mathrm{ore}$ NCs was further investigated by using SEM, EDS and mapping methods. The surface morphology and elemental structure of the biologically synthesized NCs were investigated with FE-SEM, EDS, point analysis and elemental mapping images, as depicted in Fig. 11-14, respectively. As Fig. 11 shows, a spherical and homogenous morphology of the nanoparticles deposited on the

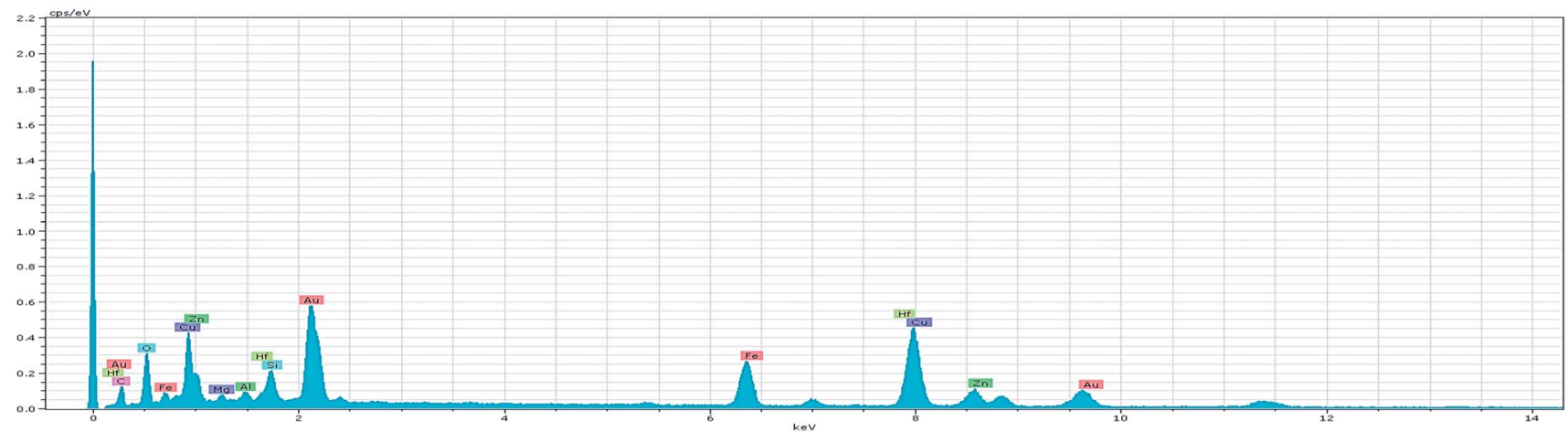

Fig. 13 Point analysis of green-synthesized $\mathrm{ZnO}$ aCuO@iron ore NCs. 

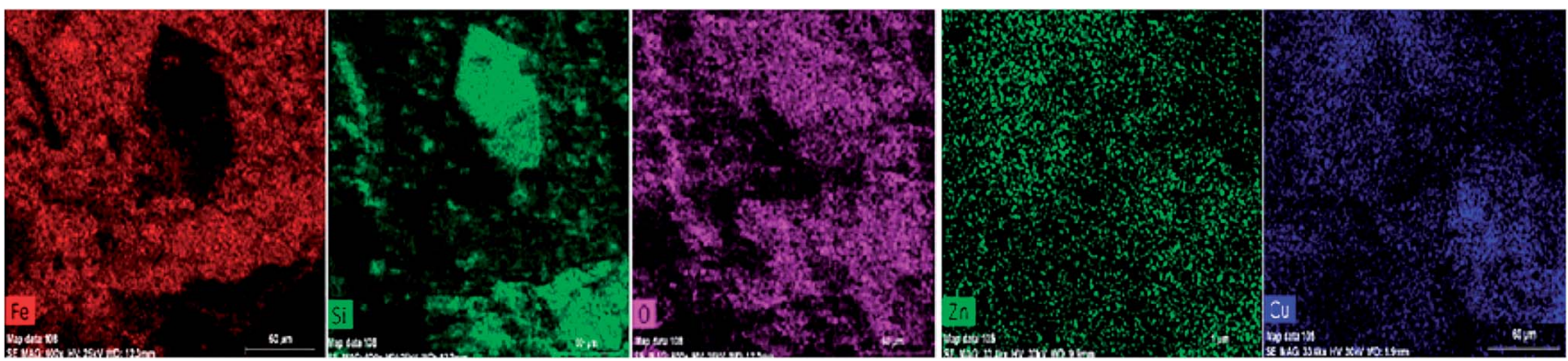

Fig. 14 Elemental mapping of the green-synthesized ZnO@CuO@iron ore NCs.
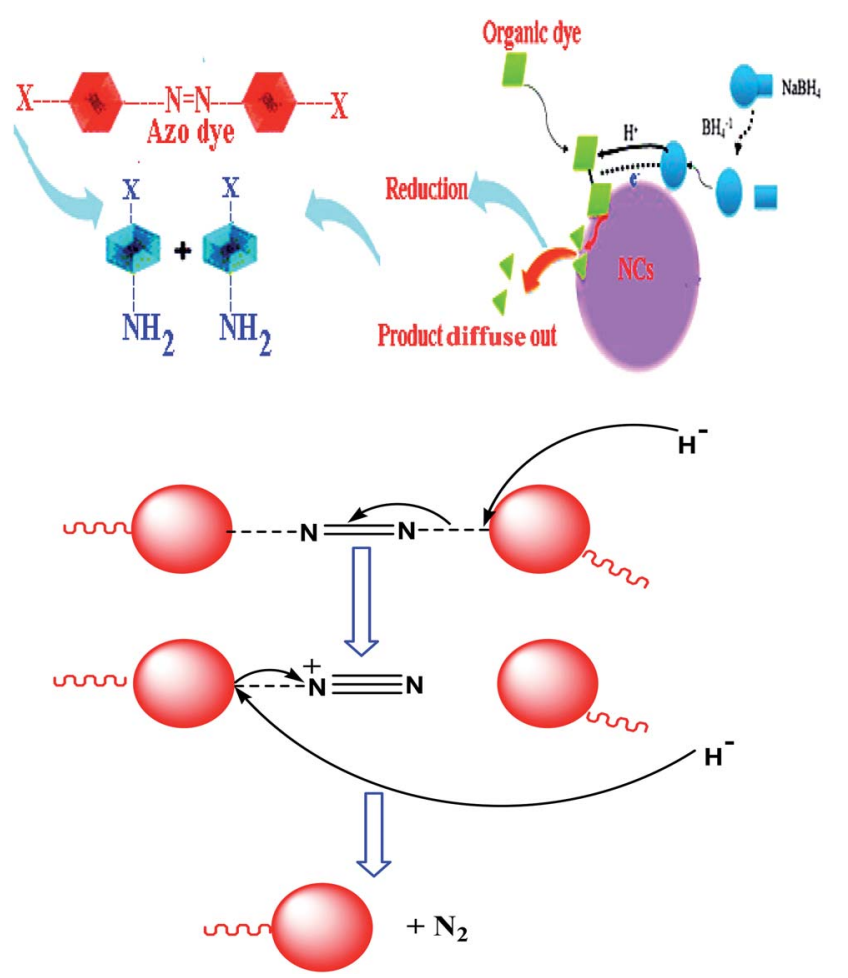

Scheme 2 Schematic of the possible mechanisms for the general reduction of organic dyes using green-synthesized NCs.

surface of iron ore with the range size mostly between $40 \mathrm{~nm}$ and $85 \mathrm{~nm}$ is visible.

Furthermore, the EDS spectrum and elemental mapping images show the chemical composition of the nanocomposite and depict the well-defined peaks of the main elements of $\mathrm{Fe}, \mathrm{O}$, $\mathrm{Zn}, \mathrm{Si}$ and $\mathrm{Cu}$; thereby these results confirm the successful anchoring of the $\mathrm{CuO}$ and magnetite NPs on the iron ore substrate, Fig. 12 and 13. Therefore, the mentioned analysis well proved the fabrication of the $\mathrm{ZnO} @ \mathrm{CuO} @$ iron ore NCs. Moreover, the result obtained by point analysis of a special section of the sample strongly supported the elemental composition obtained by the EDS result, Fig. 14 .

\section{Evaluation of antimicrobial activity of the biosynthesized ZnO@CuO@iron ore NCs}

The antibacterial activity of the green-synthesized NCs was studied against Pseudomonas aureus, Staphylococcus aureus and
Escherichia coli pathogenic bacteria by a disk diffusion method. The concentration of NCs used for this study was $1 \%(10 \mathrm{mg}$ $\left.\mathrm{mL}^{-1}\right)$ and $2 \%\left(20 \mathrm{mg} \mathrm{mL}^{-1}\right)$, and the results were compared with chloramphenicol as a positive control. All other test conditions were the same. The diameter of the appeared discs per millimetre as a minimum protection zone was reported for each of the samples. According to the ESI, Fig. 4 and Table $1, \dagger$ the plant extract demonstrated less antibacterial activity against Pseudomonas aureus, Staphylococcus aureus and Escherichia coli bacteria than the green NCs, which probably refers to the large surface area of the NCs and the accumulation of bioactive phytochemicals on its surface, as demonstrated in the FT-IR spectrum of the NCs, Fig. 14. Although, the $1 \%$ concentration of NCs demonstrated a better antibacterial potential against the nominated bacteria, the $2 \%$ concentration of NCs showed a more considerable ability for the removal of pathogenic bacteria than the $1 \%$ concentration sample and chloramphenicol as the positive control under the same conditions, which possibly showed the increasing effect of the deposited plant phytochemicals on the surface of NCs with increasing the amount of catalyst. Therefore, the amount of phytochemicals adsorbed on NCs is an important factor concerning their antibacterial activity.

\section{Evaluation of antioxidant activity of the biosynthesized ZnO@CuO@iron ore NCs}

This method is based on the reduction of antioxidants with DPPH (2,2-diphenyl-1-picrylhydrazyl) at $517 \mathrm{~nm}$ to discolouring of DPPH radicals through pairing off its odd electron. The $\mathrm{IC}_{50}$ (efficient concentration value) parameter was used for reporting the obtained results. Following the study of the antioxidant activity using this method for both the green-synthesized ZnO@CuO@iron ore NCs and ascorbic acid against gallic acid as control, the $\mathrm{IC}_{50}$ values were calculated as 29.07 and $32.61 \mathrm{ppm}$ for the green-synthesized nanocomposite and ascorbic acid, respectively. Furthermore, the radical scavenging activity of the nanocomposite in concentrations more than $300 \mathrm{ppm}$ was clearly higher than that of ascorbic acid, in which this parameter is the highest at the maximum dose of $500 \mathrm{ppm}$ $(79 \%)$ at compared with ascorbic acid (65\%) at the same concentration, see ESI, Fig. 5. $\uparrow$ The antioxidant ability of the green-synthesized nanocomposite demonstrated the deposition of a considerable amount of antioxidant phytochemicals on the surface of nanostructure, which caused an antioxidant ability 

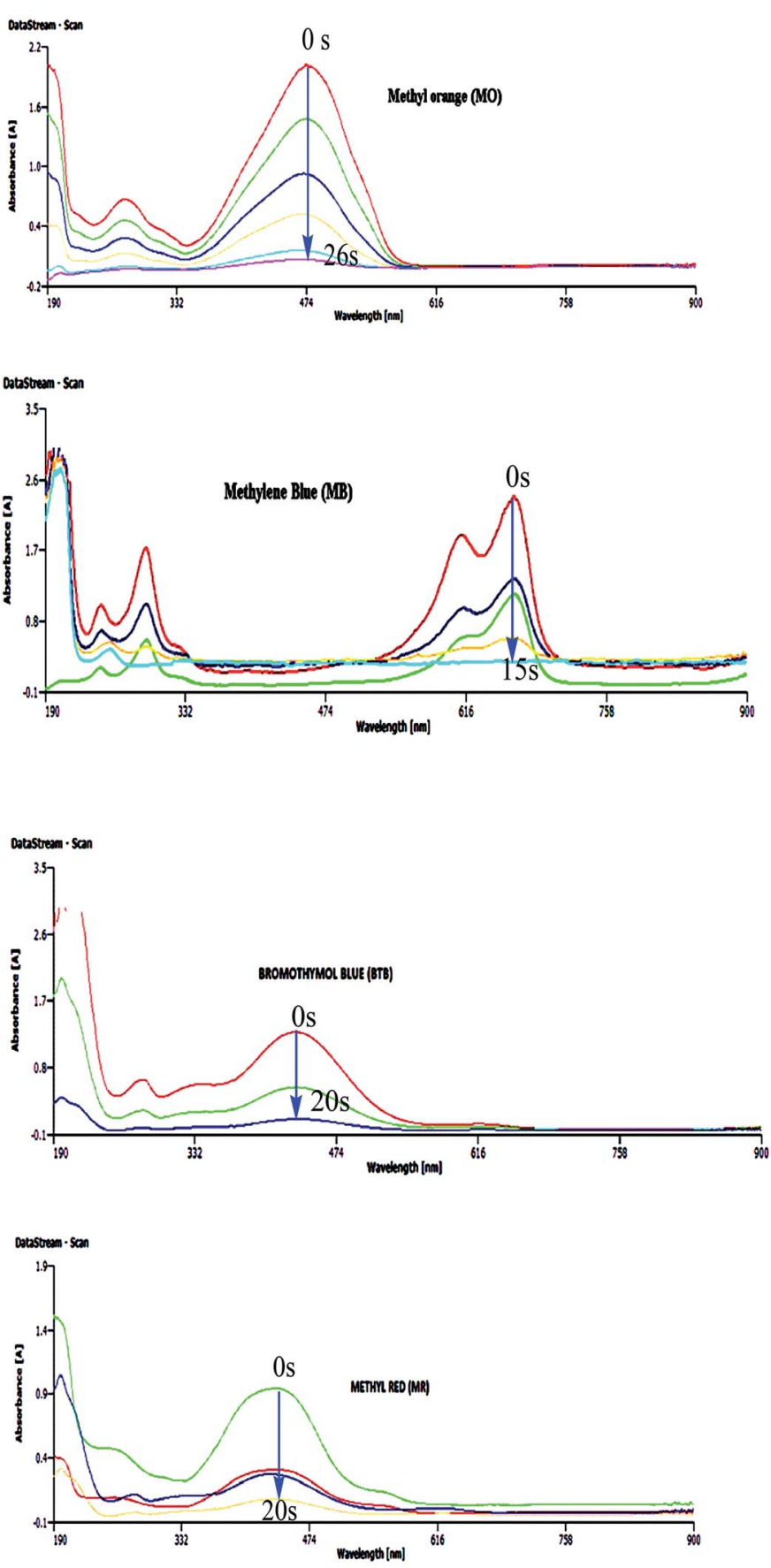

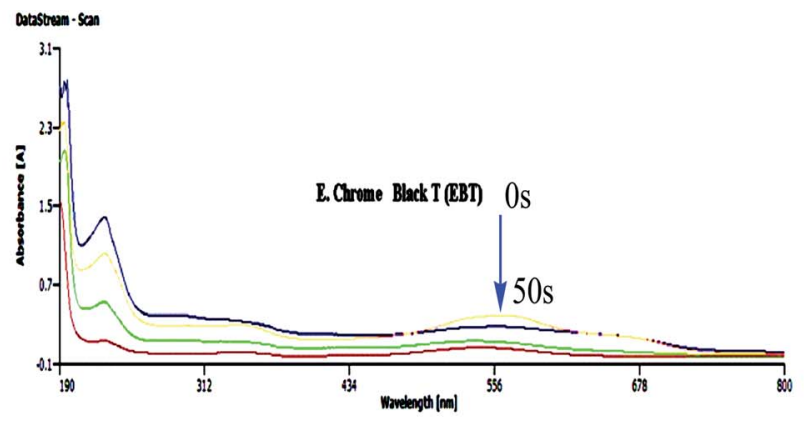

Datstom $\cdot \operatorname{sen}$
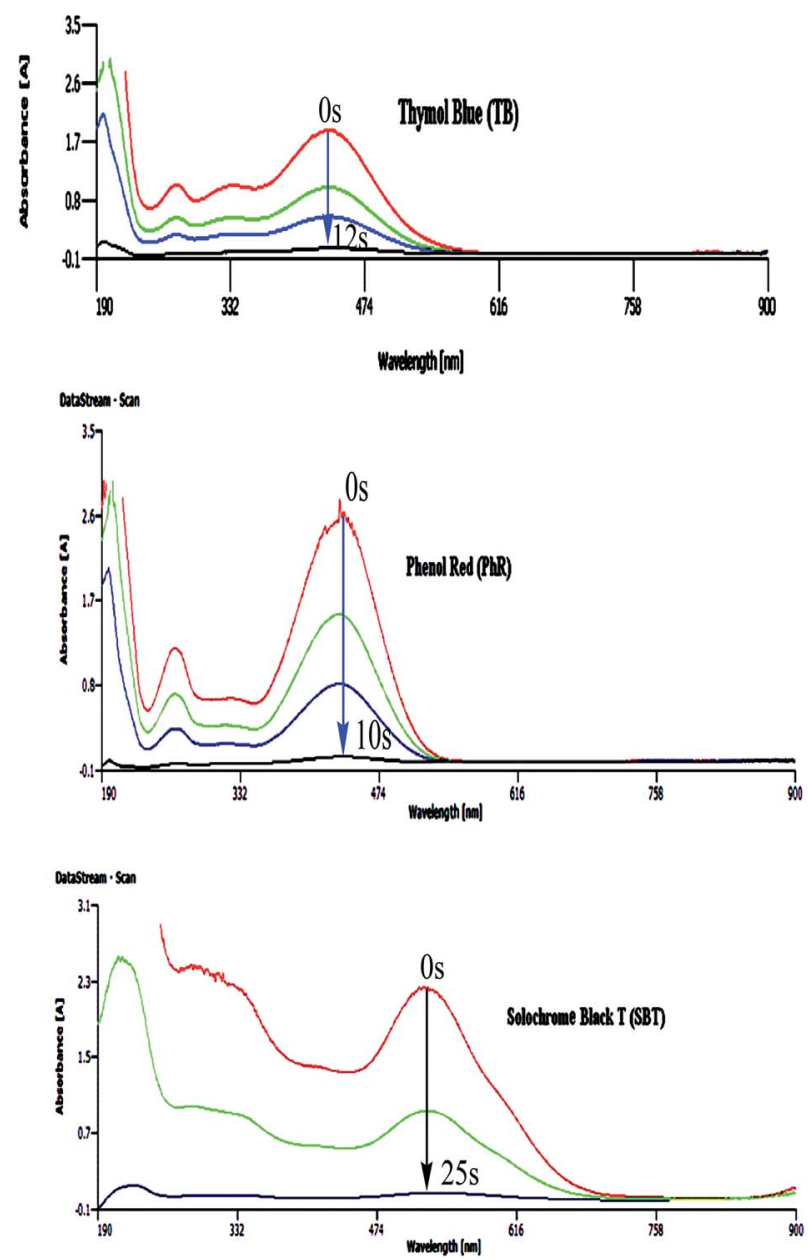

Fig. 15 Catalytic degradation of organic dyes using green-synthesized $\mathrm{ZnO}$ aCuO@iron ore NCs in the presence of $\mathrm{NaBH}_{4}$ and at ambient temperature.

around the ascorbic acid as a powerful antioxidant due to their ability to transfer a hydrogen atom or an electron.

\section{Catalytic activity of the green-synthesized ZnO@CuO@iron ore NCs for the reduction of harmful organic dyes}

The focus here is on the catalytic ability of the green-synthesized NCs for the reduction of organic dyes in the presence of $\mathrm{NaBH}_{4}$. The process benefits from the adsorption of $\mathrm{NaBH}_{4}$ onto the surface of catalyst and the formation of a metal hydride. In the next step, the organic dyes adsorb onto the surface of the catalyst and are then reduced. Finally, the reduced dyes desorb from the catalyst surface to create a free space for the reaction to continue, Scheme 2. According to Scheme 2, two possible mechanisms for the catalytic degradation of organic dyes are available: producing moieties with amine functional groups or releasing the $\mathrm{N}_{2}$ gas and producing the rest of the dye. ${ }^{12,36,37}$ 


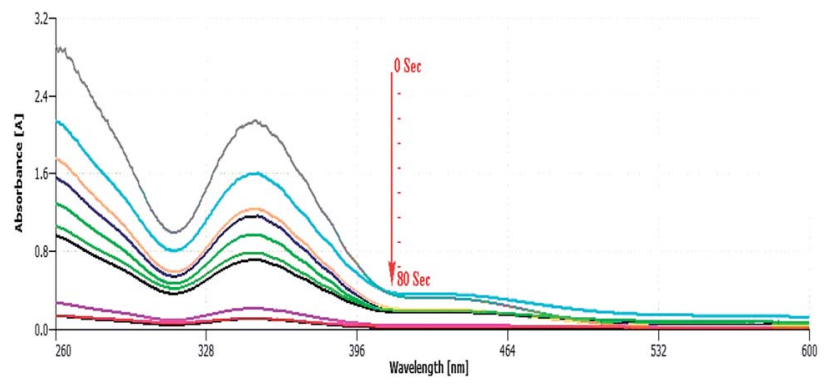

Fig. 16 Catalytic reduction of $\mathrm{Cr}^{6+}$ using green $\mathrm{ZnO}$ aCuOairon ore $\mathrm{NCs}$ in the presence of $\mathrm{K}_{2} \mathrm{Cr}_{2} \mathrm{O}_{7}$ and $\mathrm{HCO}_{2} \mathrm{H}$.

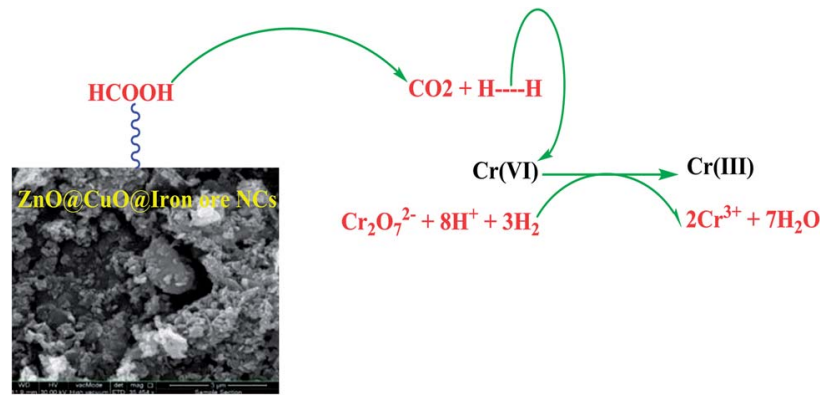

Scheme 3 Reduction mechanism of $\mathrm{Cr}(\mathrm{VI})$ to $\mathrm{Cr}(\mathrm{III})$ using green synthesized $\mathrm{ZnO}$ aCuOairon ore NCs.

Table 3 Catalytic reduction of $\mathrm{Cr}^{6+}$ using $\mathrm{ZnO}$ aCuO@iron ore NCs at $60{ }^{\circ} \mathrm{C}$

\begin{tabular}{lll}
\hline Entry & Catalyst (mg) & Time \\
\hline 1 & No catalyst & $12 \mathrm{~h}^{a}$ \\
2 & Iron ore substrate & $250 \mathrm{~s}$ \\
3 & ZnO@CuO@iron ore NCs $(2 \mathrm{mg})$ & $135 \mathrm{~s}$ \\
$\mathbf{4}$ & ZnO@CuO@iron ore NCs $(5 \mathbf{~ m g})$ & $\mathbf{8 0 ~ s}$ \\
5 & ZnO@CuO@iron ore NCs $(7 \mathrm{mg})$ & $80 \mathrm{~s}$ \\
6 & ZnO@CuO@iron ore NCs & $80 \mathrm{~s}$ \\
& $(10 \mathrm{mg})$ &
\end{tabular}

${ }^{a}$ Reaction was not completed.
Also, in order to evaluate the performance and optimum amount of the green $\mathrm{ZnO} @ \mathrm{CuO} @$ iron ore NCs in the catalytic reduction of organic dyes, different amounts of catalyst were studied and the results are summarized in Table 2 .

As reported in Table 2, the optimum amounts of the catalyst for the destruction of MO, MB, BTB, MR, EBT, TB, Ph.R and SBT were $5,3,2,3,10,1,3$ and $7 \mathrm{mg}$ respectively in the presence of $\mathrm{NaBH}_{4}$ and at ambient temperature. Further, the fastest possible degradation times of these organic dyes using the mentioned optimum amount of the catalyst were $26 \mathrm{~s}$ for MO, $15 \mathrm{~s}$ for MB, $20 \mathrm{~s}$ for BTB, $20 \mathrm{~s}$ for MR, $50 \mathrm{~s}$ for EBT, $12 \mathrm{~s}$ for TB, $10 \mathrm{~s}$ for Ph.R and $25 \mathrm{~s}$ for SBT as they were monitored spectrophotometrically by decreasing the maximum absorbance and removing the maxima while decolourizing the organic dyes, Fig. 15. Also, Table 2 reveals that there was no reaction in the absence of $\mathrm{NaBH}_{4}$ or catalyst even after passing 2 days. Thus, these are necessary parameters for the degradation process.

\section{Catalytic activity of green-synthesized ZnO@CuO@iron ore NCs for the reduction of $\mathrm{Cr}(\mathrm{vI})$}

To further study the catalytic ability of green-synthesized NCs, the reduction of $\mathrm{Cr}^{6+}$ to $\mathrm{Cr}^{3+}$ was studied spectrophotometrically. The reduction of $\mathrm{Cr}^{6+}$ to $\mathrm{Cr}^{3+}$ in the presence of potassium dichromate $\left(\mathrm{K}_{2} \mathrm{Cr}_{2} \mathrm{O}_{7}\right)$ and formic acid as a source of $\mathrm{Cr}(\mathrm{vI})$ compounds and reducing agent, respectively, was selected as a model reaction. The presence of formic acid is necessary for the process as there would be no reaction in its absence. The $\mathrm{Cr}_{2} \mathrm{O}_{7}{ }^{2-}$ had an absorption peak around $345 \mathrm{~nm}$, which originated from the electron transfer between metal $\left(\mathrm{Cr}^{6+}\right)$ and ligand (oxygen), Fig. 16. As shown in Fig. 16, after adding a specified amount of catalyst, the absorption peak at $350 \mathrm{~nm}$ gradually decreases and vanishes within $80 \mathrm{~s}$ together with the disappearance of the light-yellow colour of the reaction mixture at the end of the reaction.

The possible mechanism follows the decomposition of the formic acid into $\mathrm{H}_{2}$ and $\mathrm{CO}_{2}$ using $\mathrm{ZnO@CuO@iron} \mathrm{ore} \mathrm{NCs}$ and then the reduction of chromium $\mathrm{Cr}_{2} \mathrm{O}_{7}{ }^{2-}$ by bubbling $\mathrm{H}_{2}$ gas, Scheme 3. The best result was obtained with $5 \mathrm{mg}$ of the catalyst and $1.0 \mathrm{~mL}$ of formic acid at $60{ }^{\circ} \mathrm{C}$ (Table 3 , entry 4 ).

Table 4 Catalytic adsorption of Shaikhan crude oil aromatics at room temperature

\begin{tabular}{|c|c|c|c|c|}
\hline 1 & Iron ore substrate & $20 \mathrm{~mL}$ & 5 & $45 \min ^{a}$ \\
\hline 2 & Iron ore substrate & $20 \mathrm{~mL}$ & 10 & $45 \min ^{a}$ \\
\hline 4 & Iron ore substrate & $20 \mathrm{~mL}$ & 20 & $25 \min$ \\
\hline 5 & Iron ore substrate & $20 \mathrm{~mL}$ & 25 & $25 \mathrm{~min}$ \\
\hline 6 & ZnO@CuO@iron ore NCs & $20 \mathrm{~mL}$ & 3 & $28 \min ^{a}$ \\
\hline 9 & ZnO@CuO@iron ore NCs & $20 \mathrm{~mL}$ & 15 & $8 \mathrm{~min}$ \\
\hline
\end{tabular}

${ }^{a}$ A few adsorbed. 


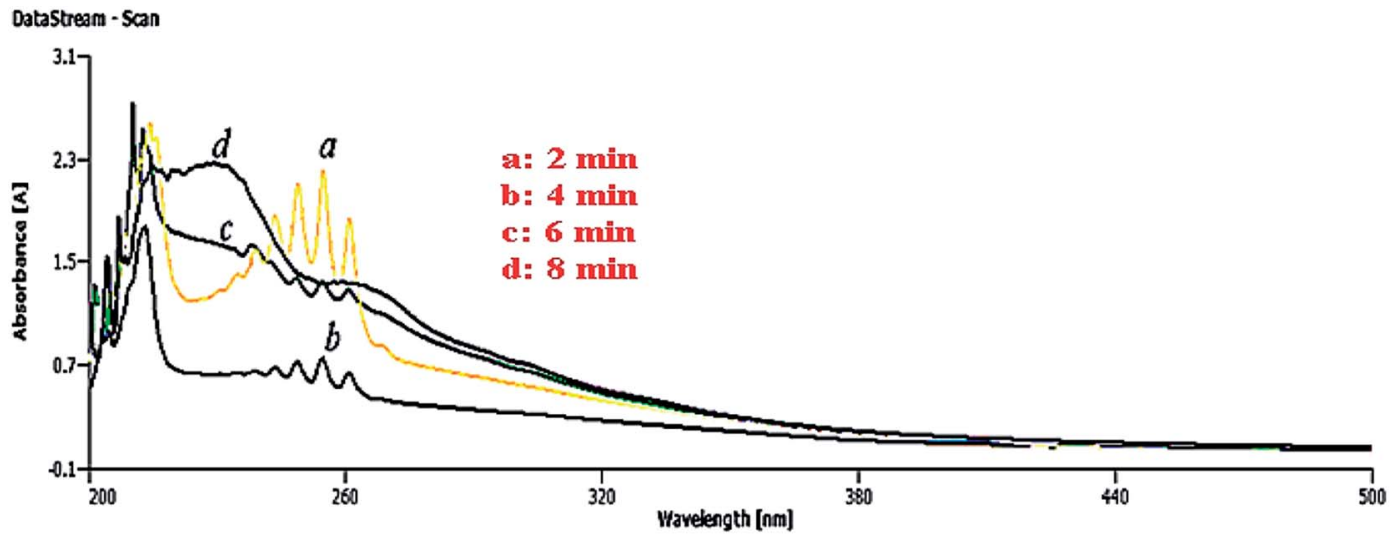

Fig. 17 Adsorption of crude oil aromatics, including PAHs, using ZnO@CuO@iron ore NCs (7 mg catalyst and $20 \mathrm{~mL}$ aromatic sample).

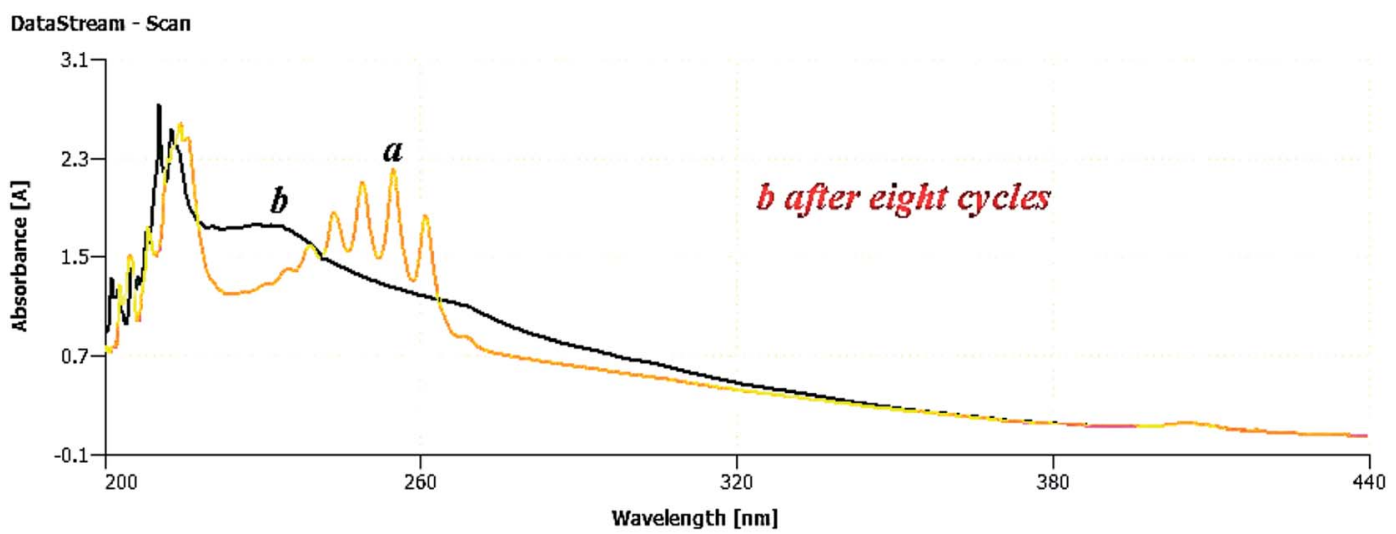

Fig. 18 UV-vis spectroscopic detection of ZnO@CuO@iron ore NCs reusability to adsorb the crude oil aromatic compounds; (a) extracted aromatics, (b) adsorption process after 8 times of reusing the catalyst.

Catalytic ability of green-synthesized ZnO@CuO@iron ore NCs to adsorb the aromatic compounds of crude oil at room temperature

The ability of NCs was tested as an adsorbant of the aromatic compounds in crude oil at room temperature, in which various amounts of the catalyst were used to optimize the process. According to Table 4, the best result was obtained using $7 \mathrm{mg}$ of the catalyst (entry 8). Also, it showed that the best result obtained by the application of the substrate (iron ore) as adsorbent solely (entry 3) was $25 \mathrm{~min}$; the application of lesser amounts of

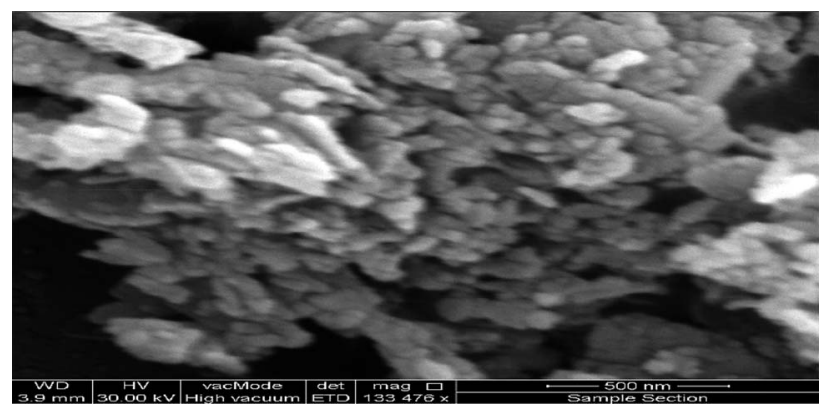

Fig. 19 SEM micrograph of green-synthesized NCs after 8 times use in the aromatic removal process. the substrate led to insignificant adsorptions even after $45 \mathrm{~min}$ (entries 1 and 2) and amounts greater than $15 \mathrm{mg}$ did not change the adsorption rate (entries 4 and 5). As previously mentioned, the best adsorption time $(8 \mathrm{~min})$ was obtained by using $7 \mathrm{mg}$ of the green catalyst (entry 8), which indicated the efficiency of $\mathrm{ZnO} @ \mathrm{CuO} @$ iron ore NCs in this process. According to entry 6 , Table 4 , the application of $3 \mathrm{mg}$ of catalyst showed no considerable adsorption signal even after $28 \mathrm{~min}$.

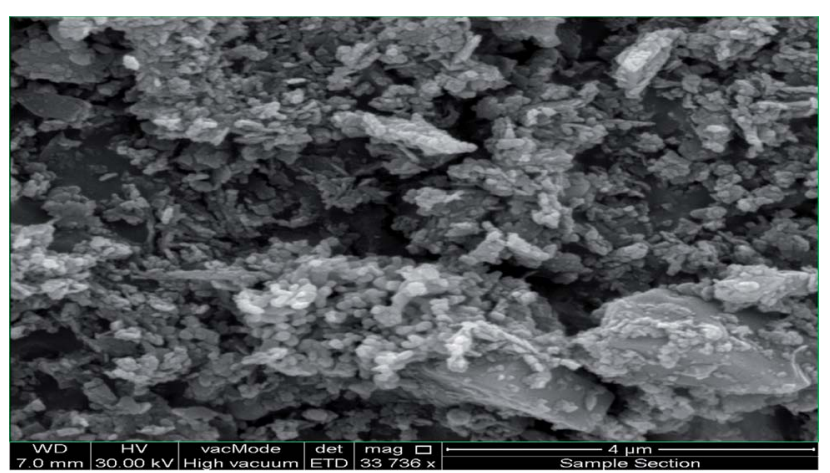

Fig. 20 XRD pattern of the ZnOaCuOairon ore NCs in the $\mathrm{Cr}^{6+}$ reduction process after 7 times being recycled. 


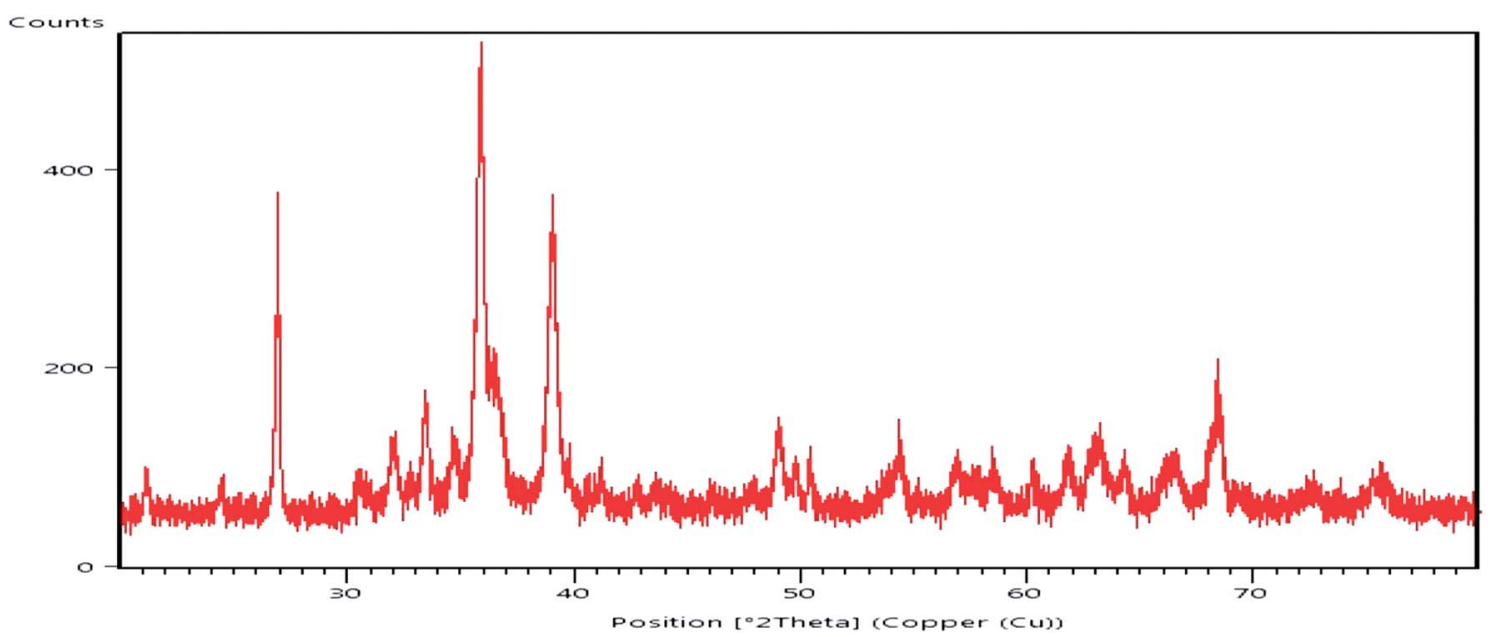

Fig. 21 XRD pattern of the $\mathrm{ZnO}$ aCuOairon ore NCs after 6 months from their green synthesis.

Finally as Table 4 shows, the time of the adsorption process decreased with increasing the amount of the catalyst.

In Fig. 17, using an optimum amount of the catalyst $(7 \mathrm{mg}$, Table 4, entry 8) for the process demonstrated a very good ability of the catalyst to adsorb the aromatics inside the sample crude oil of Shaikhan after $8 \mathrm{~min}$, in which no aromatics were detected using a UV-vis technique after this time. This ability probably refers to the presence of a considerable amount of phytochemicals on the surface of NCs, which besides the enhancement of the synergistic effect of the catalyst and its surface activity, probably captured the aromatic compounds of the crude oil through the formation of chemical bonds on the surface of the nanocatalyst, thus removing them from the sample media.

\section{Reusability, recyclability and stability of the $\mathrm{ZnO} @ \mathrm{CuO} @$ @iron ore NCs}

In this section, the reusability and recyclability of the catalyst for the $\mathrm{Cr}^{6+}$ reduction process and for the adsorption of aromatics containing PAHs from the Shaikhan crude oil sample are studied. As shown in Fig. 18, the nanocatalyst could be reused for the aromatics removal process at least 8 times with insignificant reduction of its adsorption ability.

After ending the reaction process, the catalyst was easily separated from the reaction media by filtration and washing with $n$-hexane and finally dried at room temperature. Fig. 19 shows the SEM micrograph of the separated catalyst after the 8th cycle of the reaction. The SEM micrograph and its comparison to Fig. 11 show no significant changes in its morphology, shape and size, which indicates the high stability and efficiency of the green-synthesized NCs.

Furthermore, after 7 times use in the $\mathrm{Cr}^{6+}$-reduction process, the recyclability of the catalyst in this process was investigated by SEM micrograph. After each cycle of the reaction, the catalyst was easily separated and recovered conveniently by filtration from the reaction mixture, washing with hot methanol and finally dried to use in the next cycle of the process. The SEM analysis confirmed the excellent recyclability of the catalyst after the 7th run of the reaction, in which the surface morphology, shape and size of particles did not show any deviation from its normal position, as shown in Fig. 11. Therefore, it seems that the green-synthesized nanocatalyst showed constant characteristic and high recyclability in the $\mathrm{Cr}^{6+}$-reduction process, Fig. 20.

For further investigation of the properties of the greensynthesized NCs, they were monitored after 6 months from their green synthesis. Fig. 21 depicts the XRD pattern of the green-synthesized NCs after 6 months, which in comparison to Fig. 13 simply demonstrated no significant difference with their normal position at the time of their synthesis, strongly confirming the high stability of the catalyst. It is understood here that the use of natural iron ore as a resistant substrate of the NCs and the presence of potent phytochemicals, including plant antioxidants, adsorbed on the surface of the NCs during their synthesis are the main factors that protect the catalyst from any decomposition and deformation processes and help maintain its morphology as stable and constant.

\section{Conclusions}

For the first time, a green, novel and economic strategy was employed to biosynthesize ZnO@CuO@iron ore NCs using the antioxidant content of Bryonia dioica extract and natural iron ore substrate. The synthesized NCs were well identified using XRD, SEM, EDS, elemental mapping, point analysis and FT-IR analytical techniques. The FT-IR spectrum of the NCs demonstrated the deposition of bioactive phytochemicals on the surface of the catalyst. Investigations of the antimicrobial and antioxidant potential of the green-synthesized nanocatalyst demonstrated its strong bioactivity compared to the related controls. The nanocatalyst was employed to remove crude oil aromatics, including PAHs, under mild conditions and demonstrated a high level of adsorption as monitored by UV-vis spectroscopy. Furthermore, its superior catalytic ability was monitored in the degradation process of a series of harmful organic dyes, such as MO, MB, TB, BTB, Ph.R, MR, SBT and EBT, and also in the reduction of hexavalent chromium $\left(\mathrm{Cr}^{6+}\right)$ at room temperature, with its good potential and efficiency in both 
reactions demonstrated. Moreover, the reusability and recyclability of the green catalyst for aromatics removal and the reduction of hexavalent chromium was detected using UV-vis and SEM analysis, in which its high potential was confirmed for both reactions even after the 8th and 7 th cycle of the process without losing its catalytic activity, respectively. Finally, the excellent stability of the biosynthesized ZnO@CuO@iron ore NCs was detected using XRD pattern after 6 months since their green synthesis.

\section{Conflicts of interest}

There are no conflicts to declare.

\section{Acknowledgements}

The authors gratefully acknowledge the lab facilities and technical support offered by the Scientific Research Center in Soran University to carry out this work.

\section{References}

1 M. A. Albrecht, C. W. Evans and C. L. Raston, Green Chem., 2006, 8, 417.

2 P. Dauthal and M. Mukhopadhyay, Ind. Eng. Chem. Res., 2016, 55, 9557.

3 K. B. Narayanan and N. Sakthivel, Adv. Colloid Interface Sci., 2010, 156, 1.

4 M. Hosseinkhani, M. Montazer, S. Eskandarnejad and M. K. Rahimi, Colloids Surf., A, 2012, 415, 431.

5 H. Meftahizade, J. Med. Plants Res., 2011, 17, 4310.

6 G. Schmid, Chem. Rev., 1992, 92, 1709.

7 F. Li, B. Zhang, S. Dong and E. Wang, Electrochim. Acta, 1997, 42, 2563.

8 W. Kim, J. Park, Y. Jang, Y. Chung, S. Hwang and T. Hyeon, Nano Lett., 2003, 3, 1289.

9 A. Nemamcha and J. Rehspringer, J. Phys. Chem. B, 2006, 110, 383.

10 Z. Wei, C. Xu and B. Li, Bioresour. Technol., 2009, 100, 2883.

11 S. Xuan, Y. X. J. Wang, J. C. Yu and K. C. F. Leung, Langmuir, 2009, 25, 11835.

12 M. Nasrollahzadeh, S. M. Sajadic and A. Hatamifard, Appl. Catal., B, 2016, 191, 209.

13 A. R. Phull, Q. Abbas, A. Ali, H. Raza, S. J. kim, M. Zia and I. ul Haq, Future Journal of Pharmaceutical Sciences, 2016, 2, 31.

14 W. Zhang and S. Y. Wang, J. Agric. Food Chem., 2001, 49, 5165.
15 M. Atarod, M. Nasrollahzadeh and S. M. Sajadi, RSC Adv., 2005, 5, 91532.

16 P. C. H. Hollman and I. C. W. Arts, J. Sci. Food Agric., 2000, 80, 1081.

17 M. G. Lindley, Trends Food Sci. Technol., 1998, 9, 336.

18 L. B. Colbert and E. A. Decker, J. Food Sci., 1991, 56, 1248.

19 M. Antolovich, P. D. Prenzler, E. Patsalides, S. McDonald and K. Robards, Analyst, 2002, 127, 183.

20 M. Atarod, M. Nasrollahzadeh and S. M. Sajadi, J. Colloid Interface Sci., 2016, 462, 272.

21 M. Nasrollahzadeh, S. M. Sajadi and M. Khalaj, RSC Adv., 2014, 4, 47313.

22 Z. Issaabadi, M. Nasrollahzadeh and S. M. Sajadi, J. Cleaner Prod., 2017, 142, 3584.

23 J. P. Metters, R. O. Kadara and C. E. Banks, Analyst, 2012, 137, 896-902.

24 C. E. Barrera-Díaz, V. Lugo-Lugo and B. Bilyeu, J. Hazard. Mater., 2012, 223, 1.

25 H. I. Abdel-Shafy and M. S. M. Mansour, Egypt. J. Pet., 2016, 25, 107.

26 J. He, J. J. Li, Y. Wen, H. W. Tai, Y. Yu, W. C. Qin, L. M. Su and Y. H. Zhao, Chemosphere, 2015, 128, 111.

27 N. D. Dat and M. B. Chang, Sci. Total Environ., 2017, 609, 682. 28 O. E. Orisakwe, Z. N. Igweze, K. O. Okolo and N. A. Udowelle, Toxicol. Rep., 2015, 2, 1019.

29 B. M. Yashwanth, S. Shanker Rai and K. P. Shivalinge Gowda, World J. Pharm. Pharm. Sci., 2014, 4, 1120.

30 C. Montoliu, S. Valles, J. Renau Piqueras and C. Guerri, J. Neurochem., 1994, 63, 1855.

31 A. G. Panosyan, G. M. Avetissian, V. A. Mnattsakanian, S. G. Batrakov, S. A. Vartanian, E. S. Gabrielian and E. A. Amroyan, Planta Med., 1983, 47, 17.

32 L. M. Gogilashvili and E. P. Kemertelidze, Chem. Nat. Compd., 2000, 36, 399.

33 H. R. Madan, S. C. Sharma, D. Suresh, Y. S. Vidya, H. Nagabhushana, H. Rajanaik, K. S. Anantharaju, S. C. Prashantha and P. S. Maiya, Spectrochim. Acta, Part A, 2016, 152, 404.

34 G. Clarke, K. N. Ting, C. Wiart and J. Fry, Antioxidants, 2013, $2,1$.

35 S. V. Bhat, B. A. Nagasampagi and M. Sivakumar, Chemistry of Natural Products, Narosa Publishing House, New Delhi, 2005, p. 585.

36 L. Han, S. Xue, S. Zhao, J. Yan, L. Qian and M. Chen, PLoS One, 2015, 10, 1.

37 K. Naseem, Z. H. Farooqi, R. Begum and A. Irfan, J. Cleaner Prod., 2018, 187, 296. 